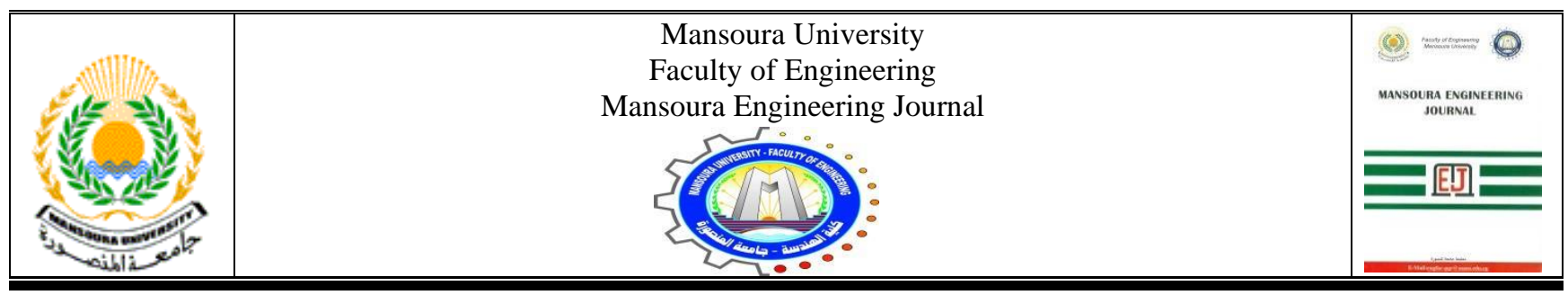

\title{
Engineering standards to achieve the quality of health services in Egyptian hospitals
}

\author{
Mohamed Helmy Elhefnawy and Zeinab Salah Mohmed
}

\begin{abstract}
KEYWORDS:
The concept of quality, the concept of accreditation, the standards of engineering quality in hospitals
\end{abstract}

\begin{abstract}
Healing diseases and getting rid of pain is a major goal of establishing hospitals as a therapeutic environment, for hospitals to achieve this goal effectively, it must have some specifications and standards that qualify them for that, including engineering quality standards, as these standards help to raise the functional performance of the medical institution and qualify it to obtain on the quality of the desired performance and includes: (security and safety, privacy, emergency, radiation safety, chemicals safety, hazardous materials and waste, infection control, fire safety) and includes a set of sub-indicators.

This research aims to elicit and measure the importance of engineering quality standards and sub-indicators within hospital buildings, Based on the theoretical study of the basic components of the quality system in general, and to determine its link to the architectural aspect of hospitals in particular. This is achieved by defining engineering standards in accordance with medical standards in hospital buildings. In addition to conducting a field study and a questionnaire of the opinions of specialists in this field to arrange engineering standards and sub-indicators according to importance, based on the opinions of the sample and the results of the field study.
\end{abstract}

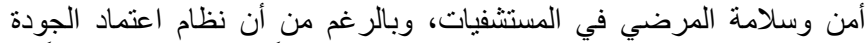

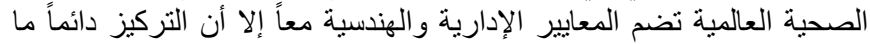

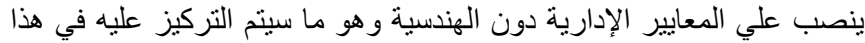

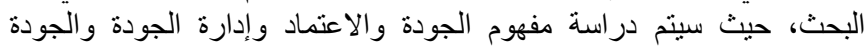

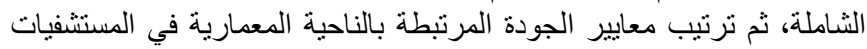

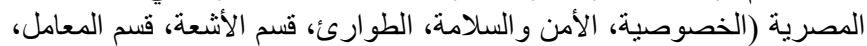

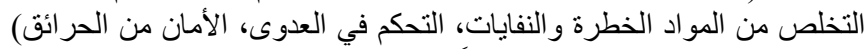

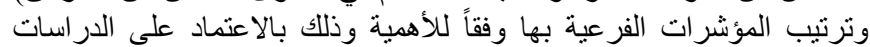

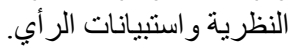
الإشكالية البحثية: - n

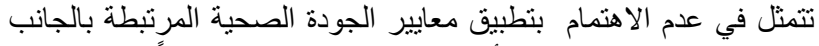

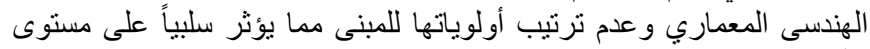
الأداء الوظيفي وتوفير بيئة آمنة للمستخدمين.

$$
\text { مظاهر الإشكالية البحثية: }
$$

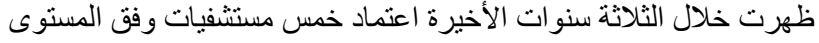

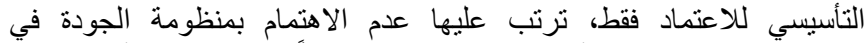

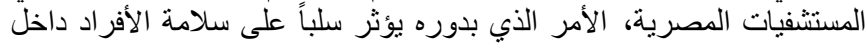

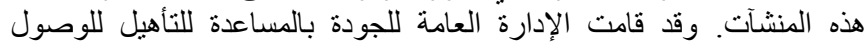
للاعتماد للمستشقيات النالية (17)

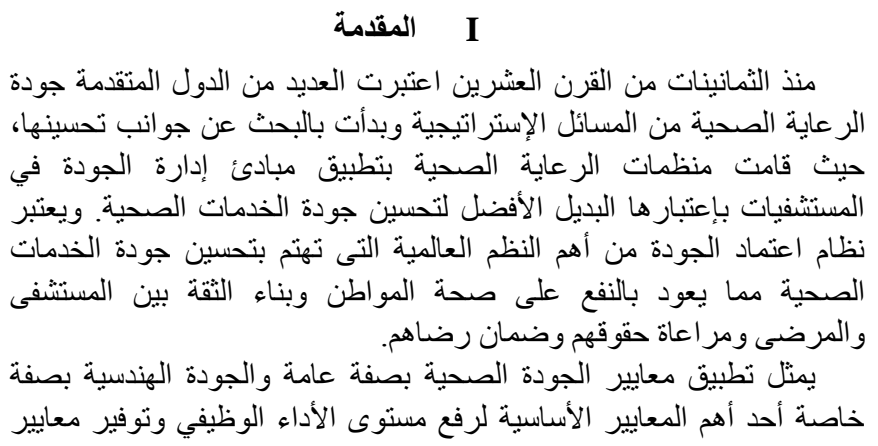

Received: (28 May, 2020) - Revised: (16 September, 2020) - Accepted: (8 October, 2020)

Mohamed Helmy Elhefnawy, Assistant Professor of Architectural Engineering, Department of Architecture, Faculty of Fine Arts, Assiut University(e-mail: mohamedhelmy@ farts.aun.edu.eg)

Corresponding Author: Zeinab Salah Mohmed, Graduate Researcher, Architectural Engineer, (e-mail: arch.zeinab.salah@gmail.com). 
ج- جودة الأداء: وترتبط بشكل مباشر بمدى قدرة المنتج على إرضاء العميل

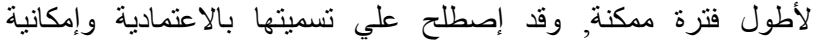
الصيانة(12). ويوضح شكل (1) مفهوم الجودة الثاملة.

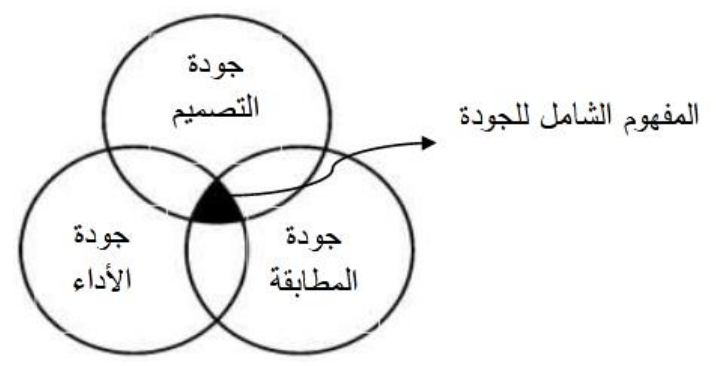

شكل (1): مفهوم الجودة الشاملة.

\section{S معايير الجودة والاعتماد في مبانى المستثفيات: III}

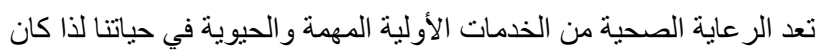

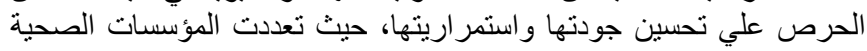

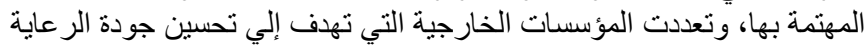

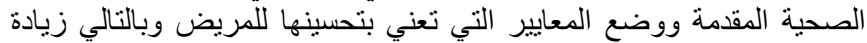

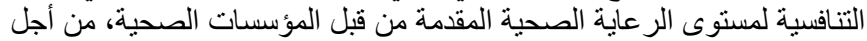

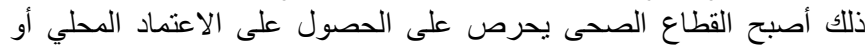

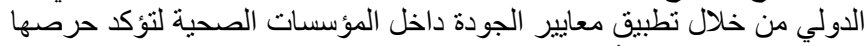
على تحقيق الجودة في أدائها ولرفع مو قعهائ التنافسي.

$$
\text { 3-3 تعريف الدعيار: }
$$

الدعيار هو: مستوى يحدد نوعية الأعمال المراد الوصول إليها أو تحقيقها

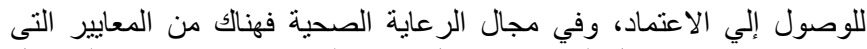

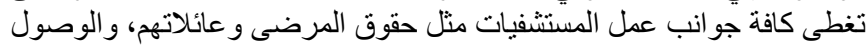

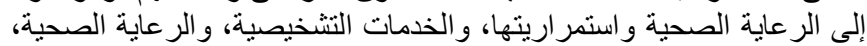

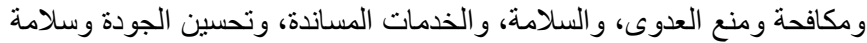

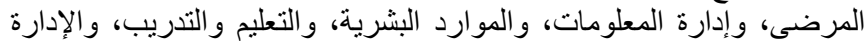

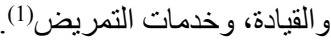

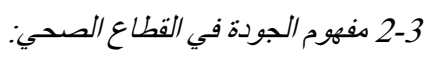

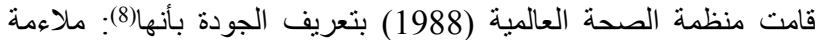

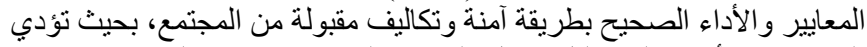

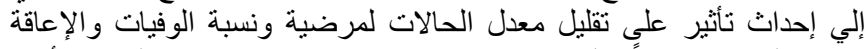

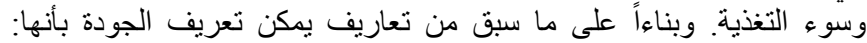

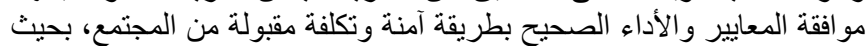

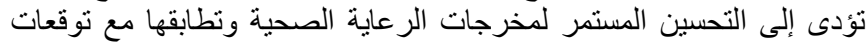

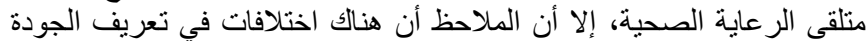
و فقا لاختلاف وجهات النظر ، فقد يعنى (مو اكبة التطور - الامتنال للمعايير - تقليل

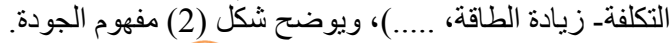

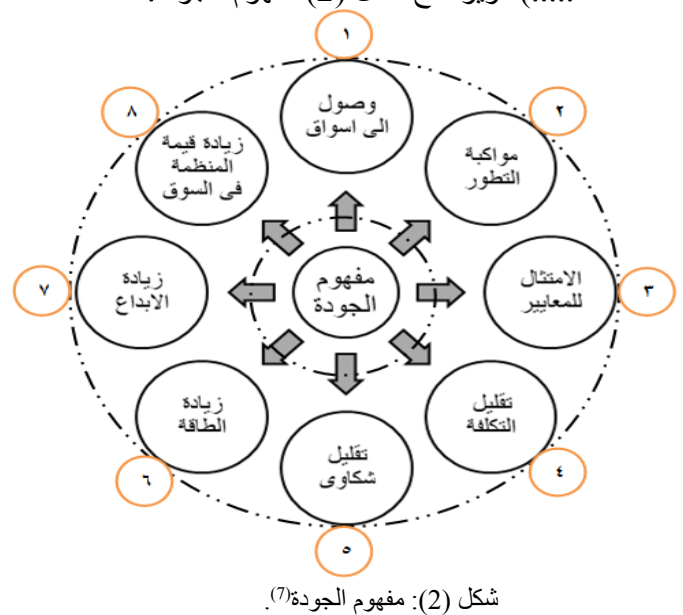

مستشفى المجمع الطبي للتأمين الصحي بطنطا- مستشفى طلبة أسبورتنج

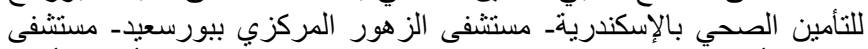

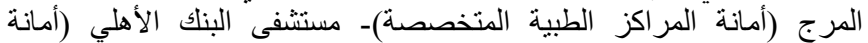

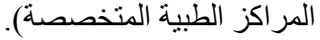

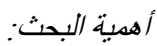

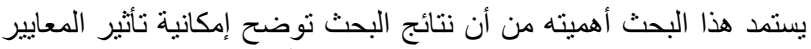

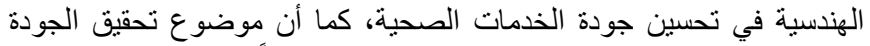

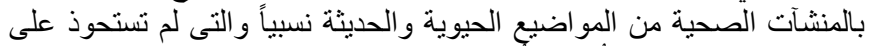

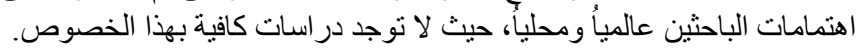

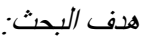

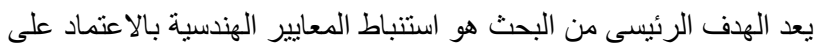

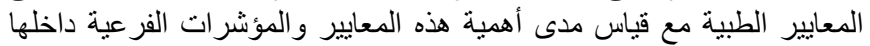

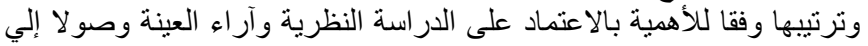
تطبيق الجودة الهندسية و الحد من المخاطر وتحقيق السلامة البيئية للمستخدمين.

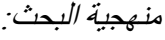

اعتمدت الدراسة على إطارين رئيسيين متكاملين هما النظرى والميدانى

بغرض تحقيق أهداف الدراسة.

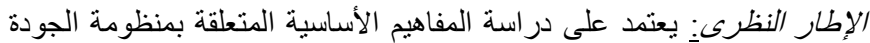

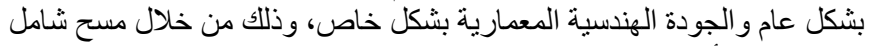

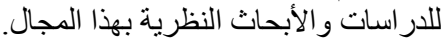

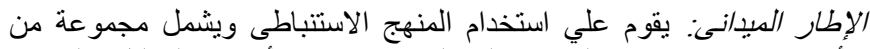

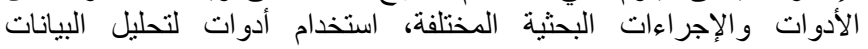

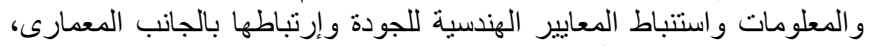

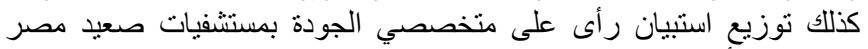
لقياس مدى أهمية هذه المعايير وصو لا إلى ترتيبها من وجهة نظر هم.

\section{المفاهيم المرتبطة بالجودة}

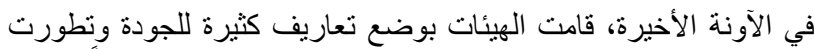

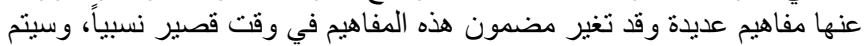
فيما يلي عرض أهم المفاهيم المرتبطة بالجودة.

1-2 1-2 - 1 فهوم الجودة:

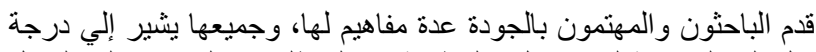

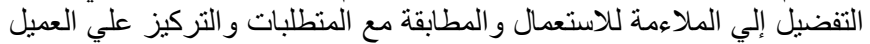

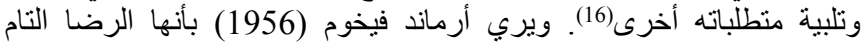

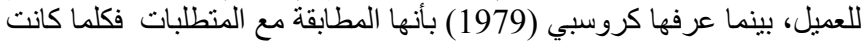

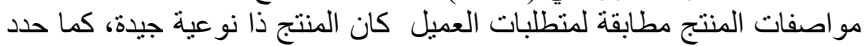
جوزيف جوران (1989) مفهوم الجودة بأنها مدى ملاعمة المنان النتجج للاستعمال بغض النظر عن وضع وحالة المنتج(9).

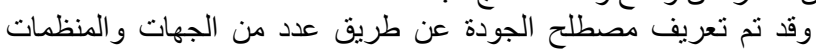

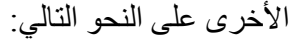
- المنظمة الدولية للتوحيد القياسي (ISO) والجمعية الأمريكية للجودة: أنها

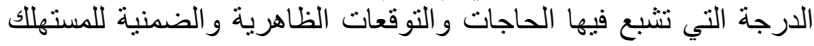

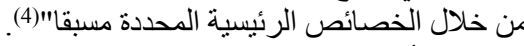

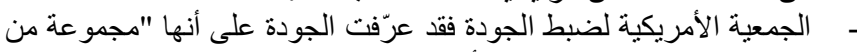
المزايا وخصائص المنتج أو الخدمة القادرة على تلبية حاجات النية

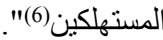

2-2 مفهوم الجودة الثاملة:

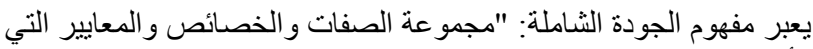

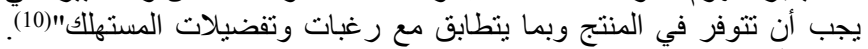
ويجب أن تثمل الجودة الجو انب الثلاثة التالية:

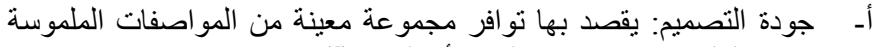

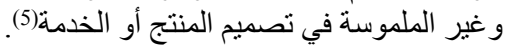

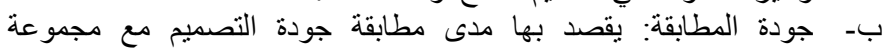
المو اصفات الموضو الفة عة للمنتج. 


\section{تحديد أولويات معايير الجودة الهندسية في المستثفيات المصرية}

IV

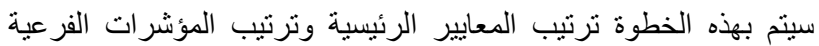

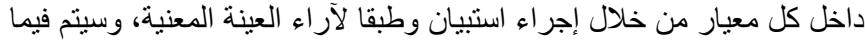

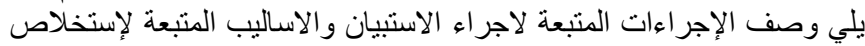

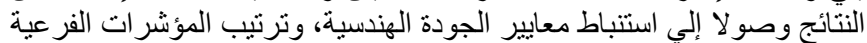

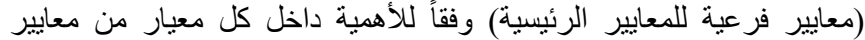
الجودة الرئيسية السابق ذكر ها سابقا، للوصول لترتيب لأوليب أولويات هذه المعايير حسب الأهمية الرئية

1-4 خطوات إجراء الاستبيان:

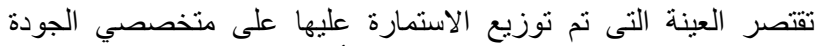

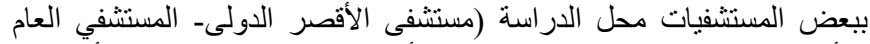

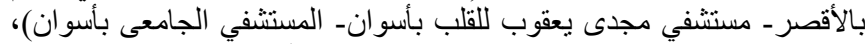
ومتخصصي الجودة بمديرية الثئون الصحية، الأطباء، والطواقي الإدارية

بصعيد مصر. وتم تحديب هذه الفئات دون غبرهم من الستتخدمين بالمستشفيات:

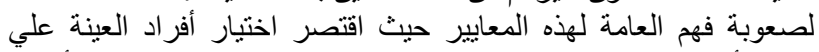

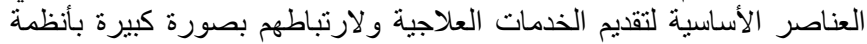
الجودة بالمستشفى، ولكونهم يتعاملون مع معظم الفر اغات الفئل المعمارية و المكونات

الأساسية للمستشفي.

وقد تم تصميم/ لستمارة الاستبيان بطريقة تسمح بالتعرف على وجهات النظر

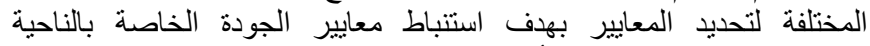

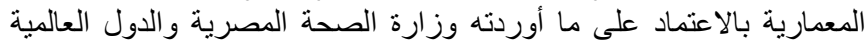

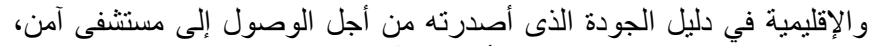
وتم تصميم الاستمارة لتتكون من الأجز اء الآتية:

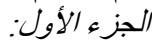

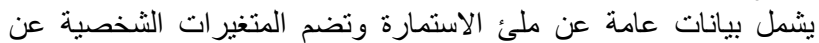
خصائص عينة الدراسة طبقا للعو امل الثخصية التالية (مكان العمل - الخبرة ) . يتضمن سؤال عن ترتيب المعايير الرئيسية الثمانية.

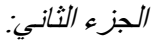

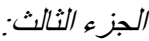

يضم مجمو عة من الأسئلة، وتم تخصيص سؤ ال لكل معيار ويشمل الأسئلة

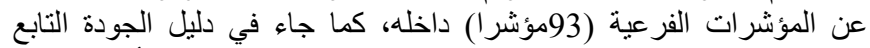

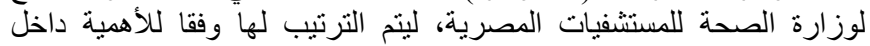

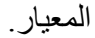

$$
\text { وقد تم تصميم أسئلة نداذج الاستبيانات بحيث تغطي نهي }
$$

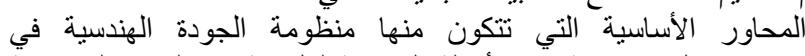

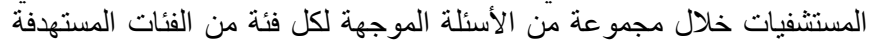

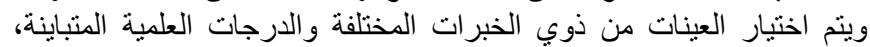

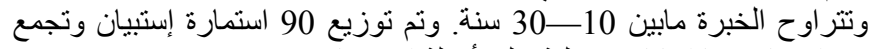
79 استمارة بها إجابات مختلفة على أسئلة الاستبيان.

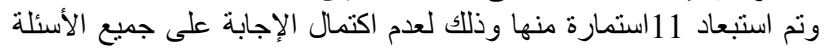

المرفقة في الاستبيان و التىى وز عت على مستثفيات حالات الدات الدراسة.

$$
\text { 2-4 الأساليب الإحصائية المتبعة في تحلبل النتائج: }
$$

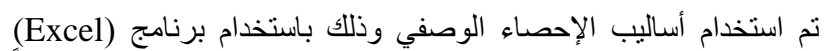

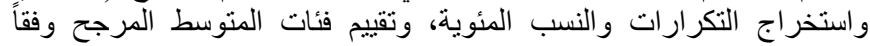
لمعايير الموافقة وعدم الموافقة، في إطار مقياس ليكرت الفئ الخماسي الاتجاه

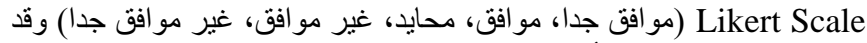

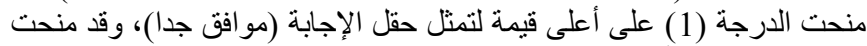

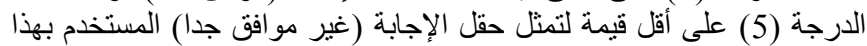

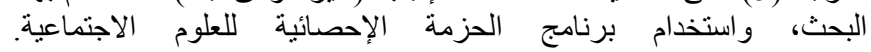
"20 إصدار (Statistical Package for Social Sciences (SPSS)) وذلكار لاستنباط و إستخراج المقاييس الوصفية (المنوسط الحسابي - الإنحراف

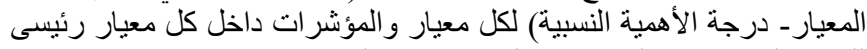
للجودة الهندسية في المستشفيات لتحقيق هدف البحث.
3-3 الاعتماد الصحي للمستشفيات: (Hospital Accreditation)

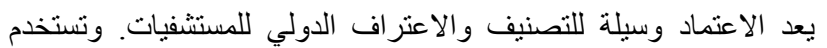

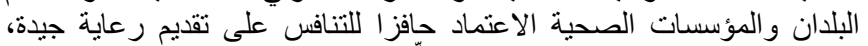

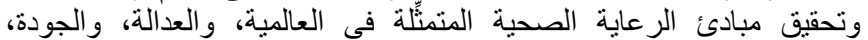

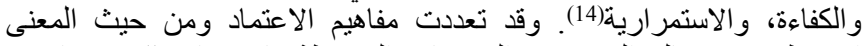

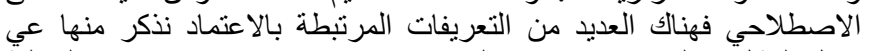
سبيل المثال لا الحصر الاعتماد والمعيار في الاعتماد ومعياير الاعتماد المحلية

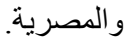

الاعتماد: هو الاعتراف بأية مؤسسة أو برنامج للرعاية الصحية استوفي عدد

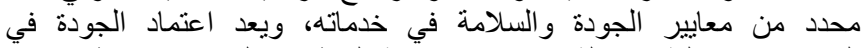

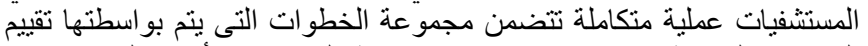

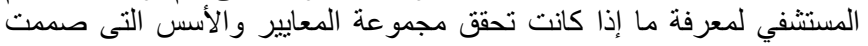
التطوير جودة الخدمات من خلال الرعاية الصحية المقدمة، وتتم عملية التئية التقييم من

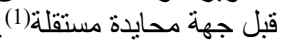

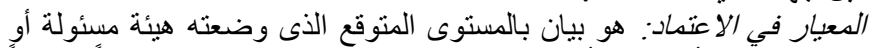

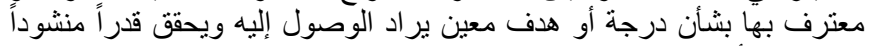

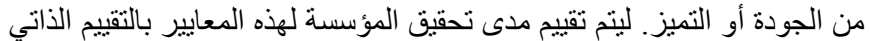

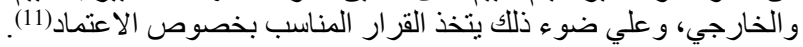

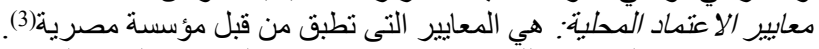

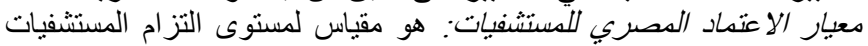

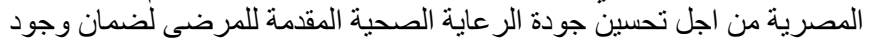

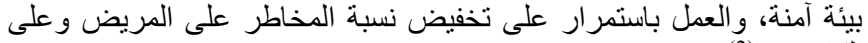

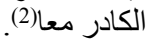

4-3 تصنيف معايير الجودة والاعتماد المصرية للمستشفيات:

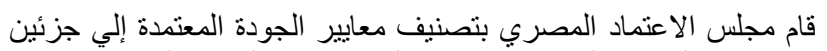

رئيسيين وهما: المعايير الطبية والإدارية والمعائية والميير غير الطبية (الهندسية).

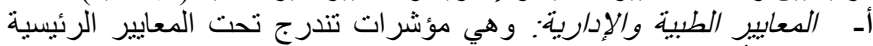

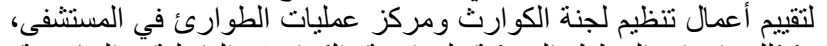

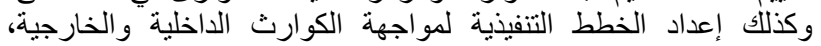

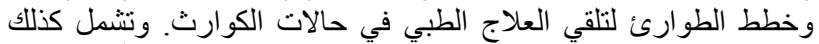
تقييم خطط التشغيل والصيانة الوقائية، واستعادة الخدمات الأساسية في المستشفى عند حدوث الأخطار (15).

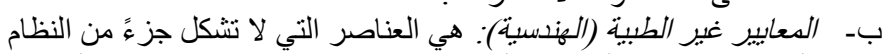

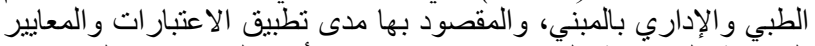

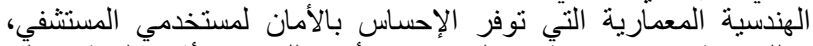

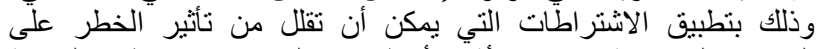

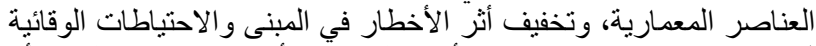

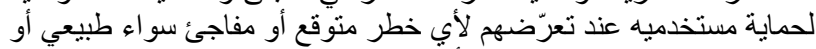

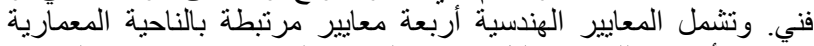

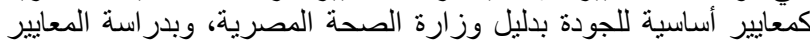

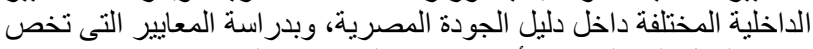

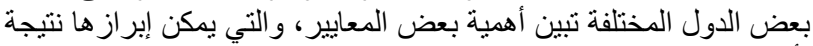

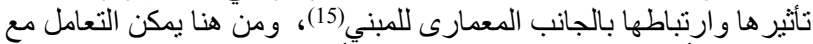

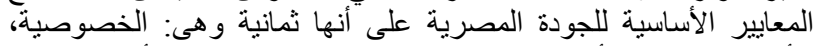

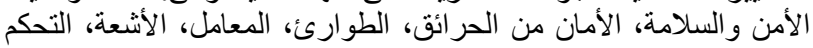

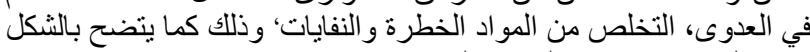

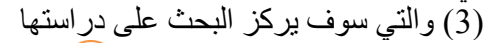

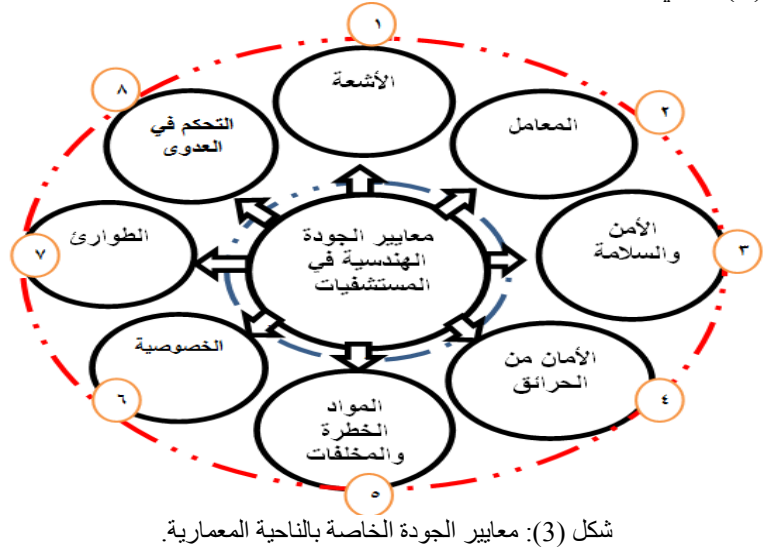




$$
\text { 1-2-3-4 المؤشرات الهامة في معيار الخصوصية: }
$$

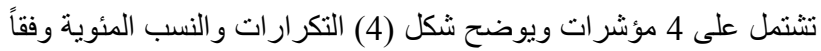

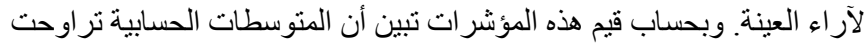

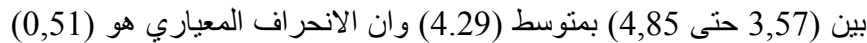

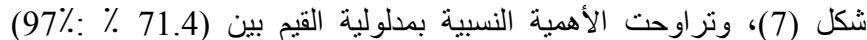

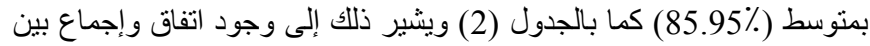
آراء العينة على اتجاههم الإيجابي المرتفع على مؤشرات معيار الخصوصية.

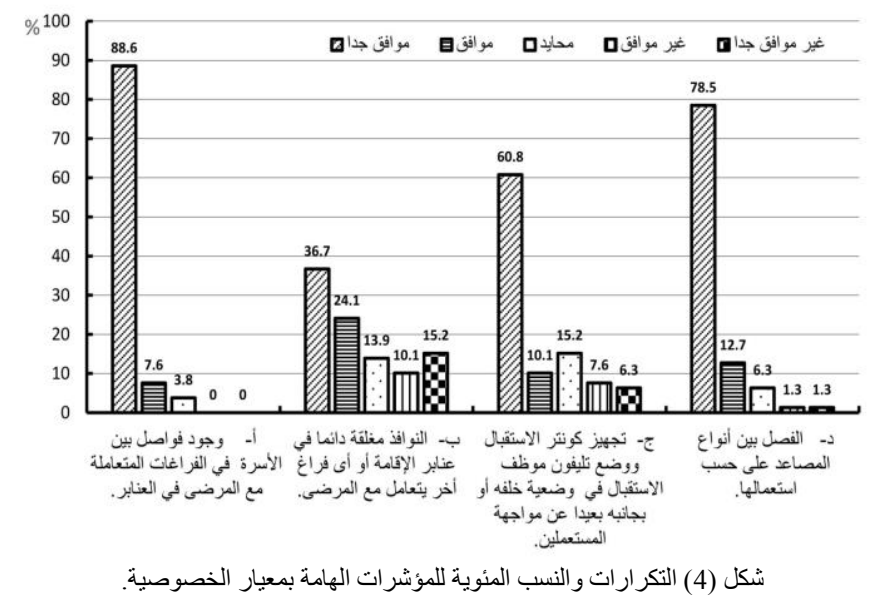

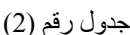

\begin{tabular}{|c|c|c|c|c|}
\hline الترتيب & الالأهمية & المعياري & الحسابي & المؤشرات \\
\hline 1 & 97.00 & 0.45 & 4.85 & 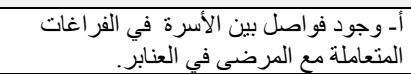 \\
\hline 4 & 71.40 & 1.45 & 3.57 & فراغ- الثو افذ يتعاملة دمع الما في عنابر الإقامة أو أى \\
\hline 3 & 82.20 & 1.28 & 4.11 & 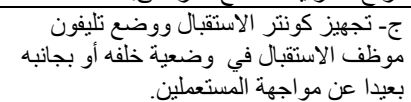 \\
\hline 2 & 93.20 & 0.76 & 4.66 & دـتعمالها. بين أنواع المصاعد على حسب \\
\hline & 85.95 & 0.51 & 4.29 & الكتو سط العام \\
\hline
\end{tabular}

يتضح من الثكل السابق الإهتمام بمؤشر وجود فواصل بين الأسرّة في الإبـا

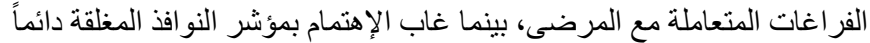

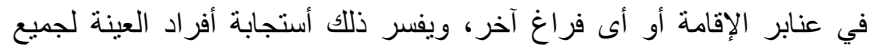

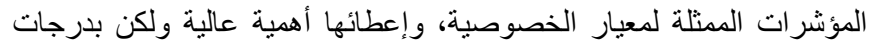

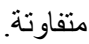

2-2-3-4 معيار الأمن والسلامة:

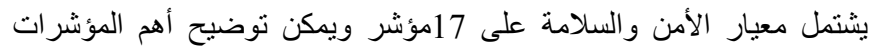

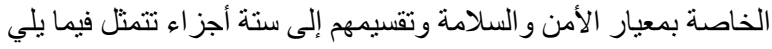

$$
\text { أ- ـ المؤشرات الهامة في معيار الأمن والسلامة: }
$$

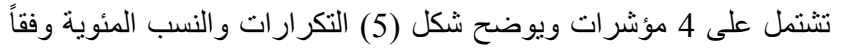

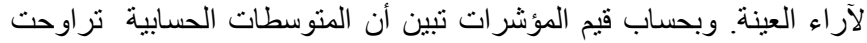

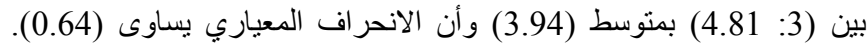

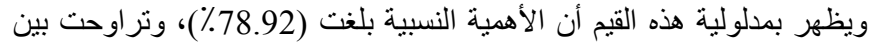

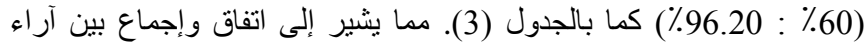
العينة على اتجاههم الإيجابي على مؤشر ات معيار الأمن و السلامة.

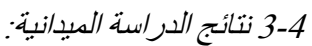
شملت نتائج الدراسة تحديد لتأثئير معايير الجودة الصحية على التصميم

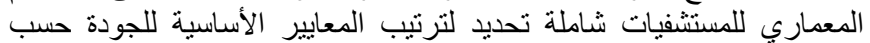

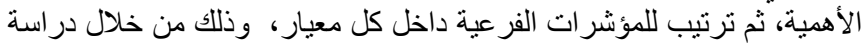

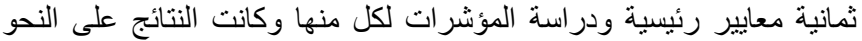
النالي:

1-3-4 ترتيب المعايير الأساسية للجودة حسب الأهبية طبقا لآراء عبنة

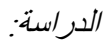

أظهرت اتجاهات أفر اد عينة البحث اتجاهاً عاماً نحو المو افقة على معايير

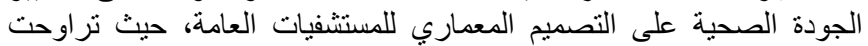

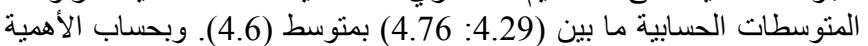

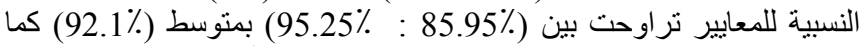
بالجدول (1) الذي يوضح ترتيب جميع المعايير حسب الأهمية.

\begin{tabular}{|c|c|c|c|c|c|}
\hline | - مترتيب & الن & المعياري & الحستوسبط & المعاييز & e \\
\hline 8 & 85.95 & 0.51 & 4.29 & |معيار الخصوصية. & 1 \\
\hline 7 & 86.21 & 0.39 & 4.31 & ] معيار الأمن و السلامة. & 2 \\
\hline 2 & 94.57 & 0.22 & 4.72 & ] معيار الأمان من الحر ائق. & 3 \\
\hline 3 & 93.80 & 0.32 & 4.68 & إسيار قسم الطو ارئ. & 4 \\
\hline 1 & 95.25 & 0.30 & 4.76 & | معيار قسم المعامل. & 5 \\
\hline 4 & 93.41 & 0.29 & 4.67 & | معيار قسم الأشعة. & 6 \\
\hline 6 & 92.43 & 0.17 & 4.62 & |معبار التحكم في العدوى. & 7 \\
\hline 5 & 92.71 & 0.24 & 4.63 & |معيار التخلص من المو اد الخطرة و النفايات & 8 \\
\hline - & 92.10 & 0.12 & 4.60 & 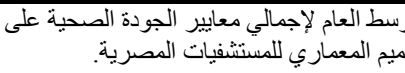 & \\
\hline
\end{tabular}

جدول (1)

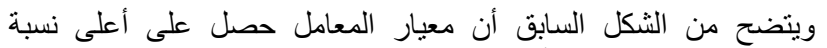
(95.25\%) ويعود ذلك إلي أن هذا المعيار حديث العهد في التطبيق بمعايير

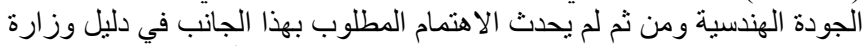

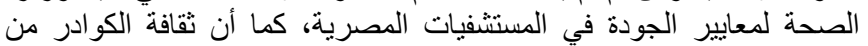

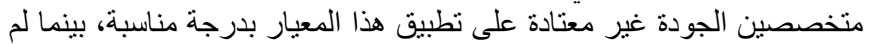

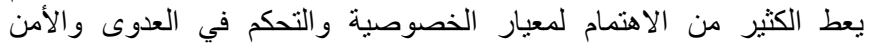

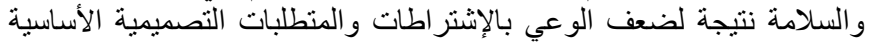

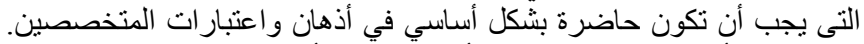

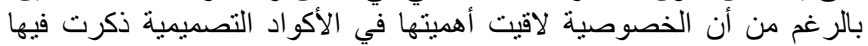

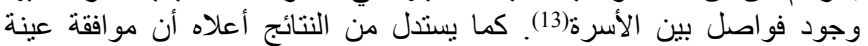

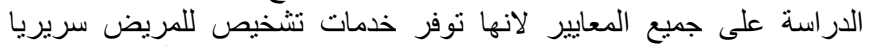

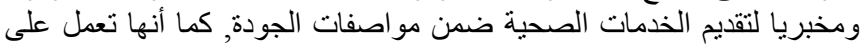

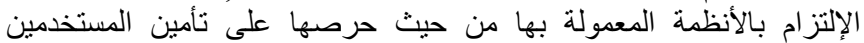

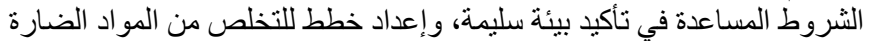

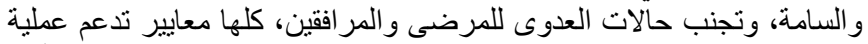
النجاح في تطبيق معايير الجودة الهندسية وتساعد على رفع مستوى الأداء الوظيفى وتحسين مستوي بيئة العمل للمستخدمين.

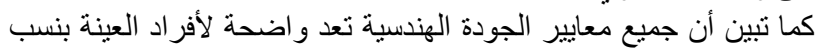

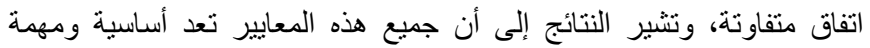
لتطبيق معايير الجودة الهندية ويمكن اعتمادها بثكل فعال في المستئشفيات المصرية. - المطين

2-3-4 ترتيب المؤشرات الخاصة بكل معيار من معابير الجودة حسب الأهبة طبقا لآراء عبنة الدراسة:

فيما يلي يتم تناول التكرارات والنسب المئوية والتئية والمقاييس الإحصائية

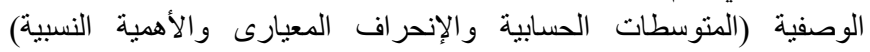

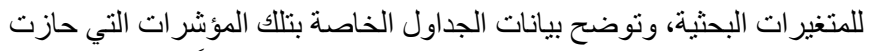

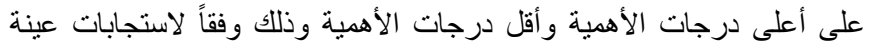

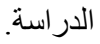




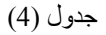

\begin{tabular}{|c|c|c|c|c|}
\hline الترتيب & النسبية & 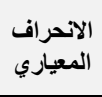 & المسابي & المؤشرات \\
\hline 1 & 96.80 & 0.41 & 4.84 & لمنع الإنزيلاق. الجرانيت المستخدم في السلالم \\
\hline 2 & 94.40 & 0.76 & 4.72 & 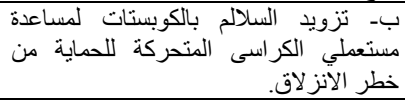 \\
\hline 4 & 92.20 & 0.83 & 4.61 & الجر- تزود على الحركة. الحمامات بعوارض تساعد \\
\hline 5 & 77.20 & 1.36 & 3.86 & دإز التهه واستخدامه كوسيلة نخريبت. الأثاث في وذللك لمنع \\
\hline 3 & 93.20 & 0.76 & 4.66 & 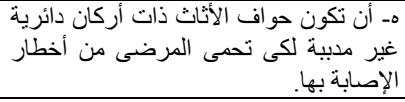 \\
\hline & 90.23 & 0.41 & 4.51 & العام \\
\hline
\end{tabular}

يتضح من الشكل السابق الإهتمام بمؤشر تخشين السلالم، وعدم الاهتمام بمؤشر

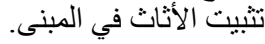

ج- مؤشرات ملائمة لحماية المناطق ذات الوظائف المهية بقسم الولادة:

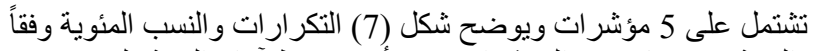

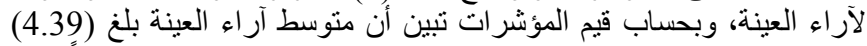

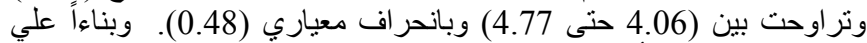

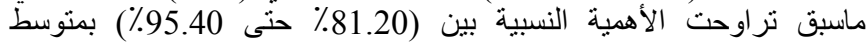

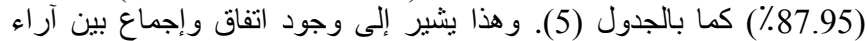

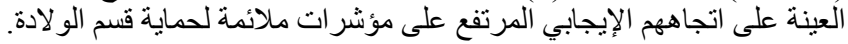

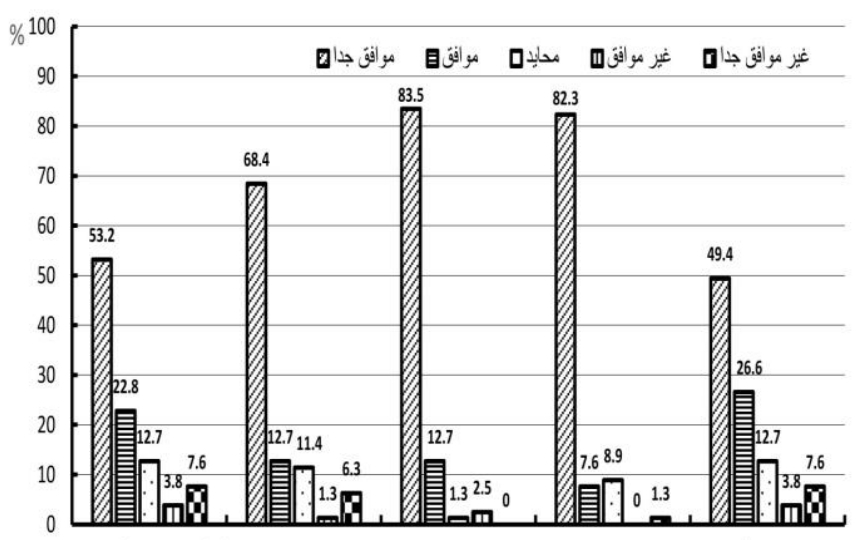

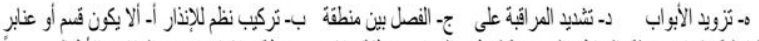

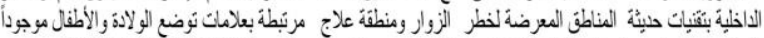

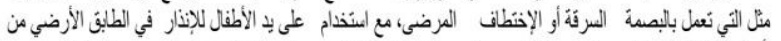

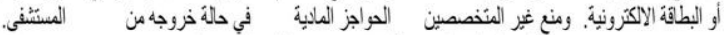

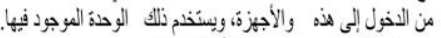

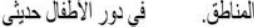

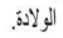

شكل (7): التكر ارات و النسب المئوية لؤُشر ات (قسم الو لادة) في معيار الأمن و السلامة.

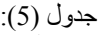

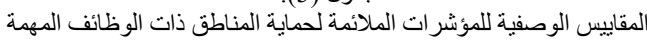
(قسم الو لادة) في معيار الأمن والسلامة.

\begin{tabular}{|c|c|c|c|c|}
\hline الترتيب & 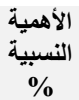 & 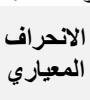 & الحستبط & المؤشرات \\
\hline 4 & 82.00 & 1.22 & 4.10 & موجوداً في ألطون قسم أو عنابر الو لادة و الأطفال \\
\hline 3 & 87.00 & 1.14 & 4.35 & 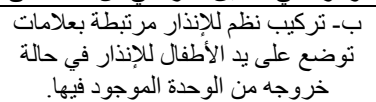 \\
\hline 1 & 95.40 & 0.59 & 4.77 & 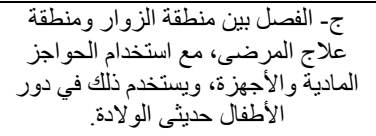 \\
\hline
\end{tabular}

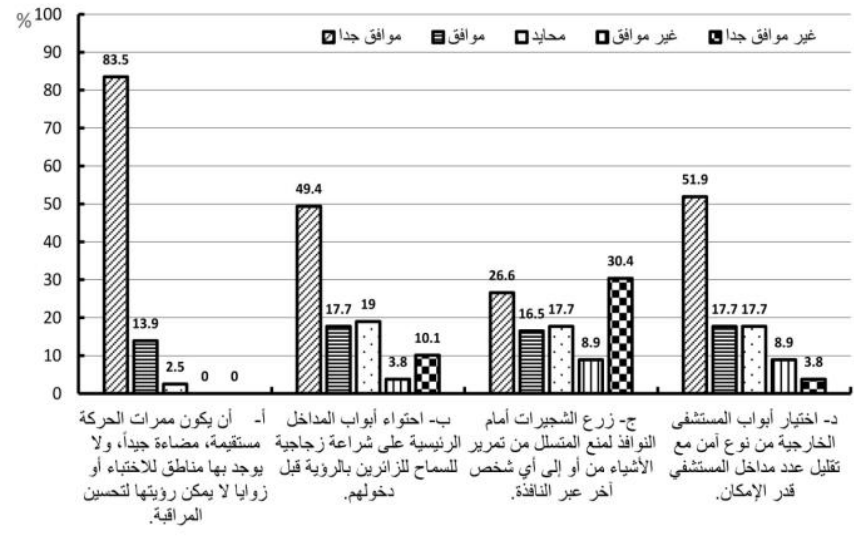

شكل (5) التكرارات و النسب المئوية للمؤشر ات الهامة في معيار الأمن و السلامة.

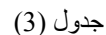

\begin{tabular}{|c|c|c|c|c|}
\hline الترتيب & الألهبية & 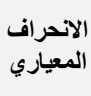 & المستوسط & المؤشرات \\
\hline 1 & 96,20 & 0,45 & 4,81 & 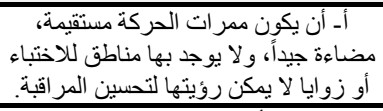 \\
\hline 3 & 78,40 & 1,32 & 3,92 & 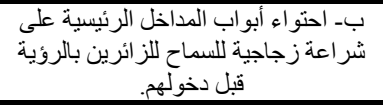 \\
\hline 4 & 60,00 & 1,60 & 3,00 & المتسلل من تمرير الأشياء من أو أو إلى أني أني \\
\hline 2 & 81,00 & 1,18 & 4,05 & 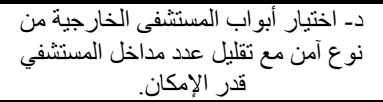 \\
\hline & 78,92 & 0,64 & 3,94 & المتوسط العام \\
\hline
\end{tabular}

يتضح من الشكل السابق إهتمام أفر اد العينة بمؤشر ممر ات الحركة، بينما لم يتم

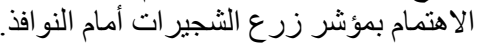

ب- المؤشرات الاحتياطية في معبار الأمن والسلامة:

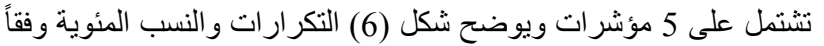

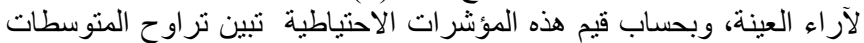

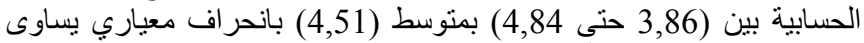
(0,41). وبلغ منوسط الأهية النسبية (40,23\%) وتراوحت ما بين (47,20)

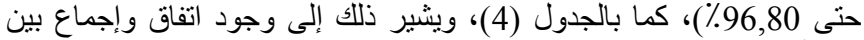
آر اء أفر اد العينة على اتجاههم الإيجابي المرتفع على هذه, المؤشرات الثرات

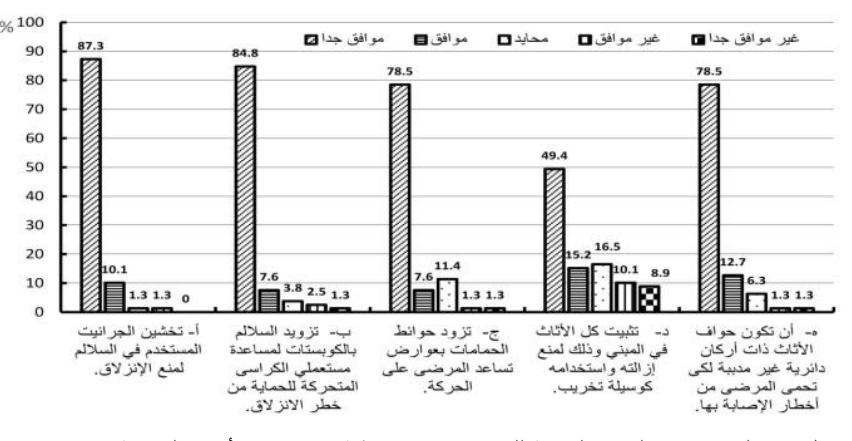

شكل (6) التكرارات و النسب المئوية للمؤشر ات الاحتياطية في معيار الأمن والسلامة. 


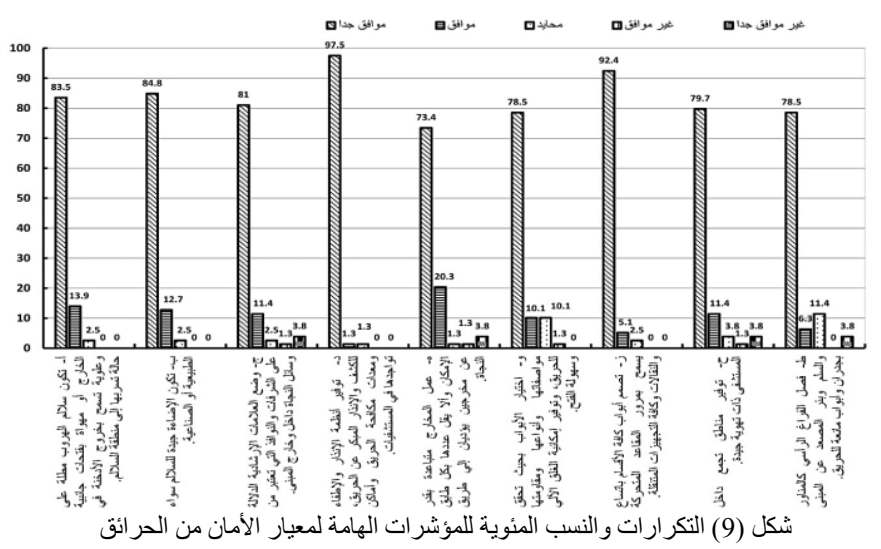

يتضح من الجدول التالي أن أعلى مؤشر حصل على إهتمام العينة هو

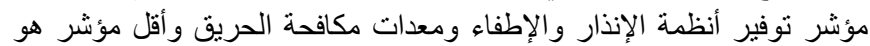

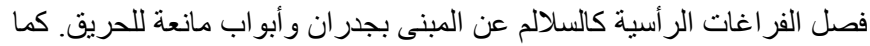

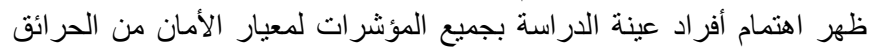
ولكن بدرجات متفاوت

\begin{tabular}{|c|c|c|c|c|}
\hline \multirow[b]{2}{*}{ الترتيب } & \multicolumn{4}{|c|}{ المقاييس الوصفية للمؤشر ات الهامة في مـ } \\
\hline & $\begin{array}{l}\text { الأهمبية } \\
\% \\
\%\end{array}$ & 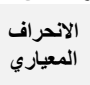 & المستبط & المؤشرات \\
\hline 4 & 96.20 & 0.45 & 4.81 & 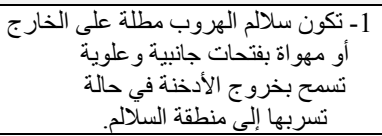 \\
\hline 3 & 96.40 & 0.44 & 4.82 & 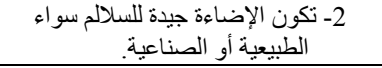 \\
\hline 6 & 93.00 & 0.90 & 4.65 & 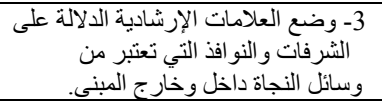 \\
\hline 1 & 99.20 & 0.25 & 4.96 & 4 و و الإنذار المبكر الإنذار والحريق، الإطفاء للكثيف \\
\hline 8 & 91.60 & 0.90 & 4.58 & 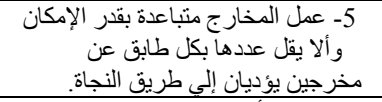 \\
\hline 5 & 93.20 & 0.71 & 4.66 & 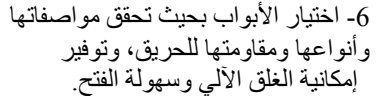 \\
\hline 2 & 98.00 & 0.37 & 4.90 & 7- بمرور المقاعد ألتواب كافة الأقسام باتسات والتقاع يسمح \\
\hline 7 & 92.40 & 0.92 & 4.62 & 8- نوفير مناطق تجمع داخل المستشفى \\
\hline 9 & 91.20 & 0.97 & 4.56 & 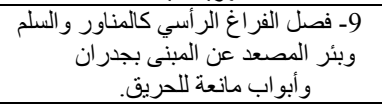 \\
\hline- & 94.57 & 0.22 & 4.72 & المتوسط العام \\
\hline
\end{tabular}

4-2-3-4 معيار قسم الطوارئ:

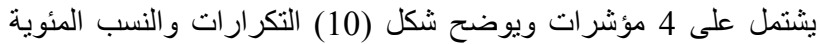
وفقاً لآراء العينة، وبحساب قيم المؤشرات تبين أن متوسط الآراء (4.68)

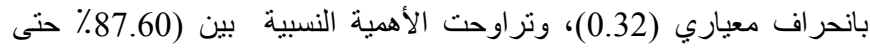

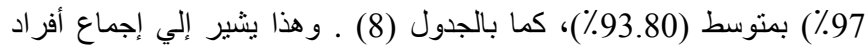
العينة على اتجاههم الإيجابي المرتفع على مؤشر اتل بات معيار قسم الطوارئ.

\begin{tabular}{|c|c|c|c|c|}
\hline 2 & 94.00 & 0.74 & 4.70 & 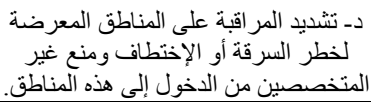 \\
\hline 5 & 81.20 & 1.21 & 4.06 & 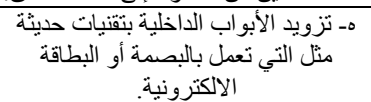 \\
\hline
\end{tabular}

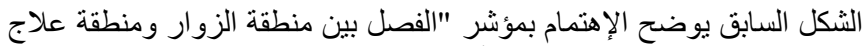

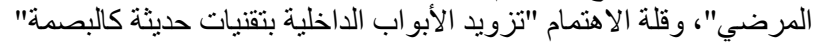

$$
\text { دـ المؤشرات الخاصة بمعيار الأمن والسلامة. }
$$

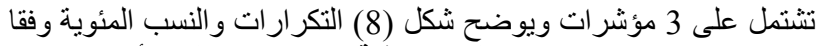

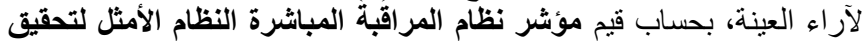

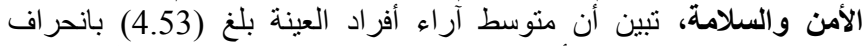

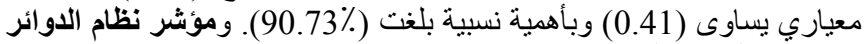

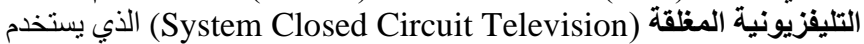

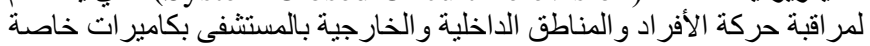

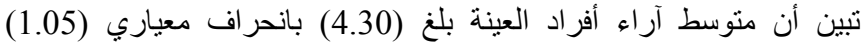
وبأهمية نسبية (86.08\%). ومؤشراستخدام النظام الآلى لمراقبة لوحات أرقام السيارات (ANPR)) (System

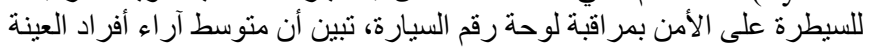

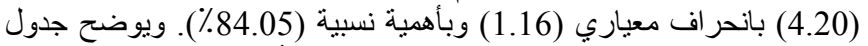

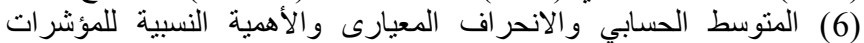
الخاصة بمعيار الأمن والسلامة.

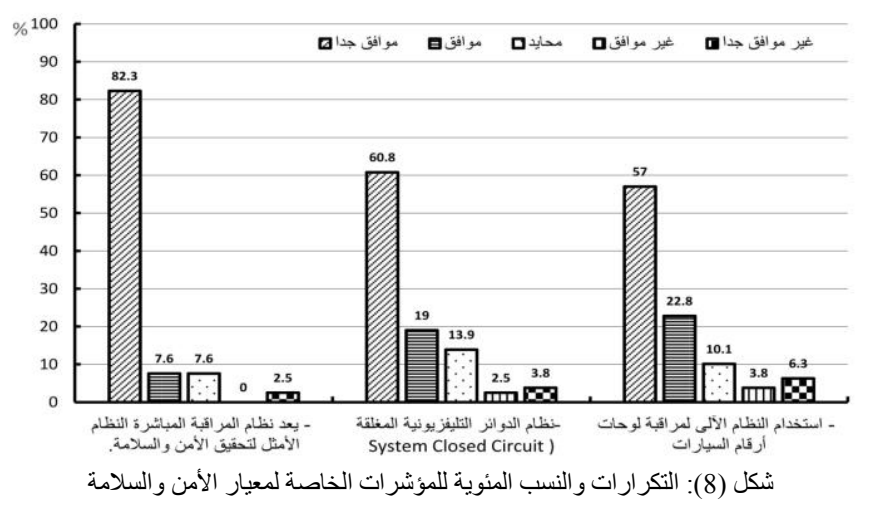

\section{جدول (6) (6)}

\begin{tabular}{|c|c|c|c|}
\hline الألهبية & المعياري & الحسابي & مؤشر \\
\hline 90.73 & 0.41 & 4.53 & ـ الأنظ و السلامة. المبة المبانشرة النظام الأمثل لتحقيق \\
\hline 86.08 & 1.05 & 4.30 & ـ مؤشر نظام الدو ائر التليفزيونية المغلقة. \\
\hline 84.05 & 1.16 & 4.20 & 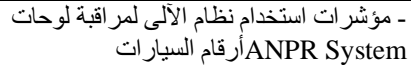 \\
\hline
\end{tabular}

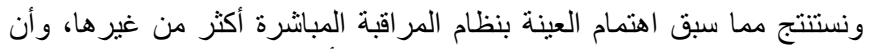

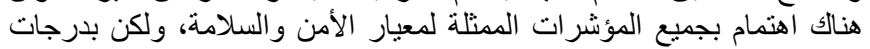

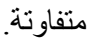

$$
\text { 3-2-3-4 المؤشرات الهامة في معيار الأمان من الحرائق: }
$$

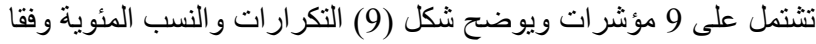
لآراء العينة، وبحساب المؤشرات تراوحت قيت بئ المتوسطات الحسابية تراوحت

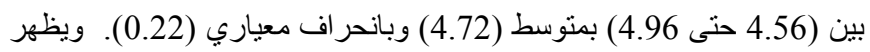

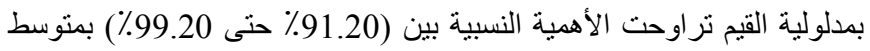

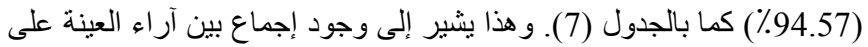
اتجاههم الإيجابي المرتفع على مؤشر ات معيار الأمان من الحرائق. 


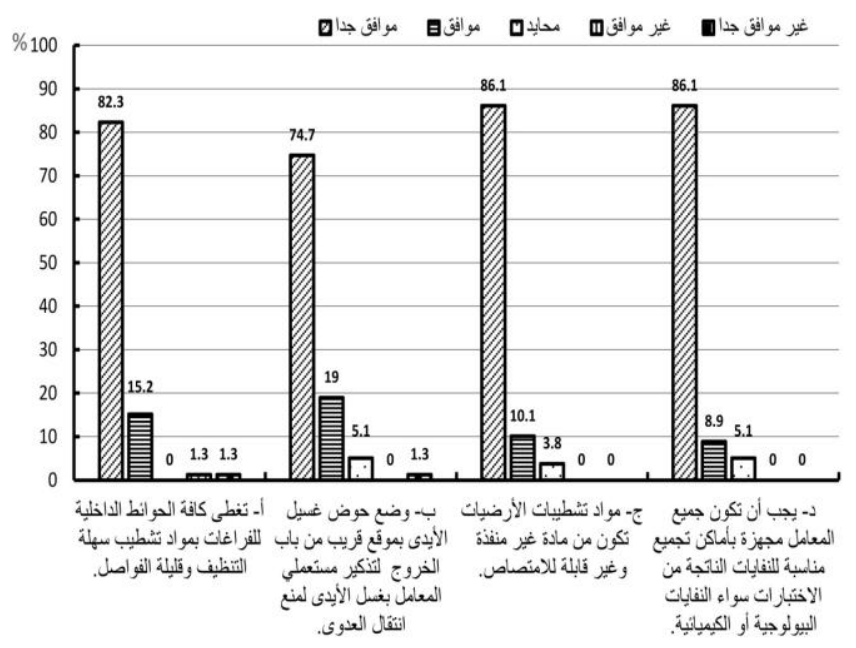

شكل (11): التكرار ات و النسب المئوية للمؤشر ات الهامة في معيارقسم المعامل.

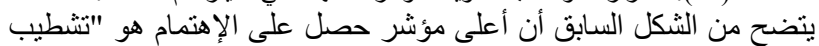

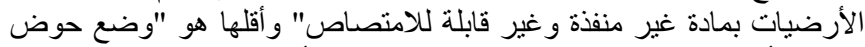

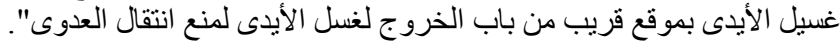
جدول (9) (9) (9)

\begin{tabular}{|c|c|c|c|c|}
\hline الترتيب & $\begin{array}{c}\text { النسبية } \\
\text { الأهمية } \\
\end{array}$ & 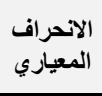 & المتوسط & المؤشرات \\
\hline 3 & 95.20 & 0.64 & 4.76 & أـ تغطى كافة الحو ائط الداخلية للفر اغات بمو \\
\hline 4 & 93.20 & 0.69 & 4.66 & 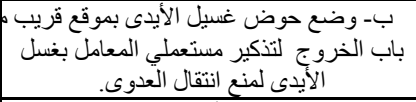 \\
\hline 1 & 96.40 & 0.47 & 4.82 & 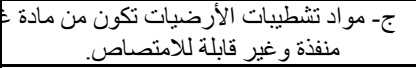 \\
\hline 2 & 96.20 & 0.50 & 4.81 & 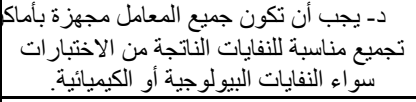 \\
\hline- & 95.25 & 0.30 & 4.76 & المتوسط العام \\
\hline
\end{tabular}

6-2-3-4 معبار قسم الأشعة:

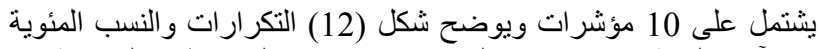

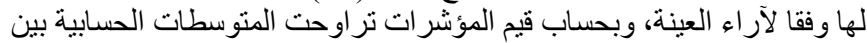
(4.47 حتى 4.90) بمتوسط (4.67) بانحر اف معياري(

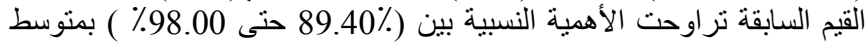

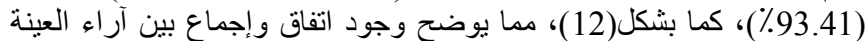

على اتجاههم الإيجابي المرتفع على المؤشرات الهامة في معيار قسم الأشعة.

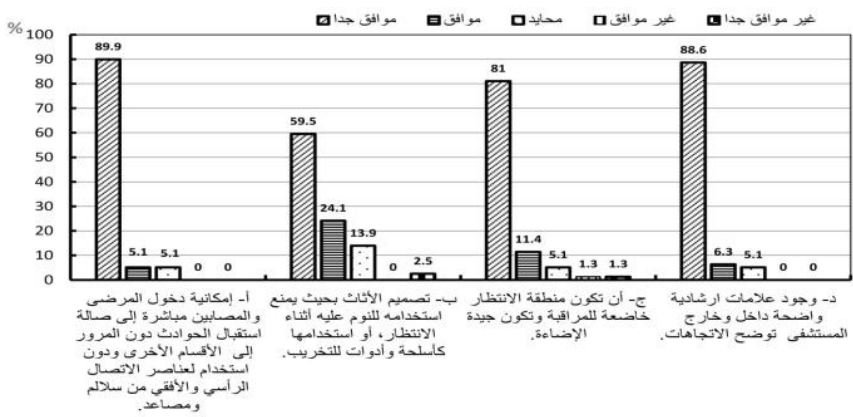

شكل (10): النكر ارات و النسب المئوية للمؤشر ات الهامة لمعيار قشم الطوارئ.

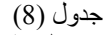

\begin{tabular}{|c|c|c|c|c|}
\hline الترتيب & $\begin{array}{l}\text { النسبية } \\
\text { الأهمبة } \\
\text { النسبة }\end{array}$ & 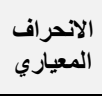 & المستوسط & المؤشرات \\
\hline 1 & 97.00 & 0.48 & 4.85 & 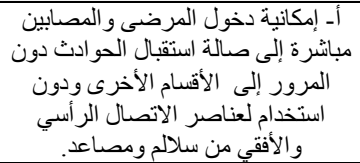 \\
\hline 4 & 87.60 & 0.91 & 4.38 & 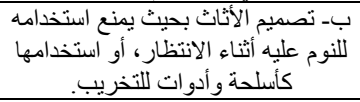 \\
\hline 3 & 94.00 & 0.74 & 4.70 & ج- ألمر تكبة وتكون منطقة الانتظار الإضاءة. \\
\hline 2 & 96.80 & 0.49 & 4.84 & داخل وخارج المبني توضات ارشادية واضاتجاهات \\
\hline - & 93.80 & 0.32 & 4.68 & المتوسط العام \\
\hline
\end{tabular}

بتضح من الثكل السابق أن أكثر المؤشرات إهتماماً هو " إمكانية دخول

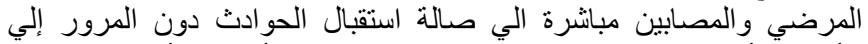

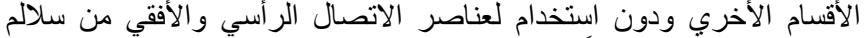

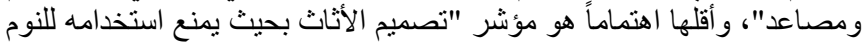

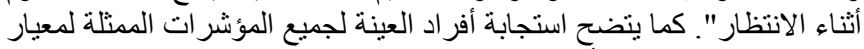

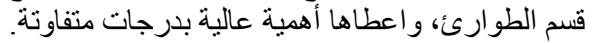

$$
\text { 5-2-3-4 معبار قسم المعامل }
$$

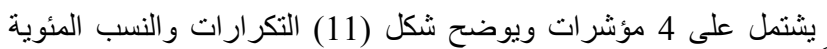

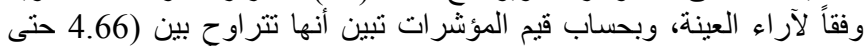

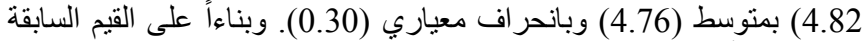

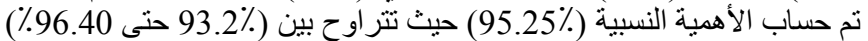

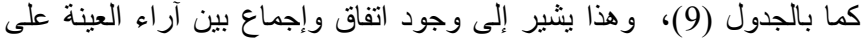
اتجاههم الإيجابي المرتفع على المؤشر ات الهامة في معيار قسم المعامل.

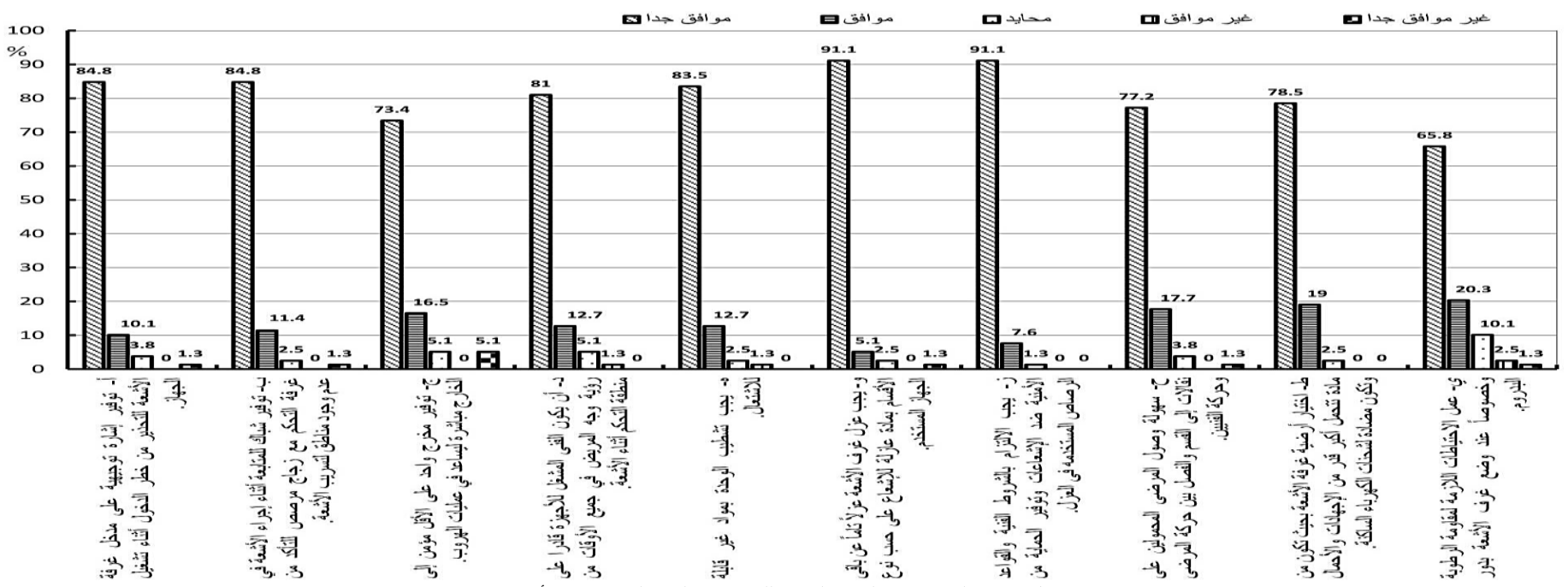
شكل (12): التكرارات و النسب المئوية للمؤشرات الهامة لمعيار قسم الأشعة. 


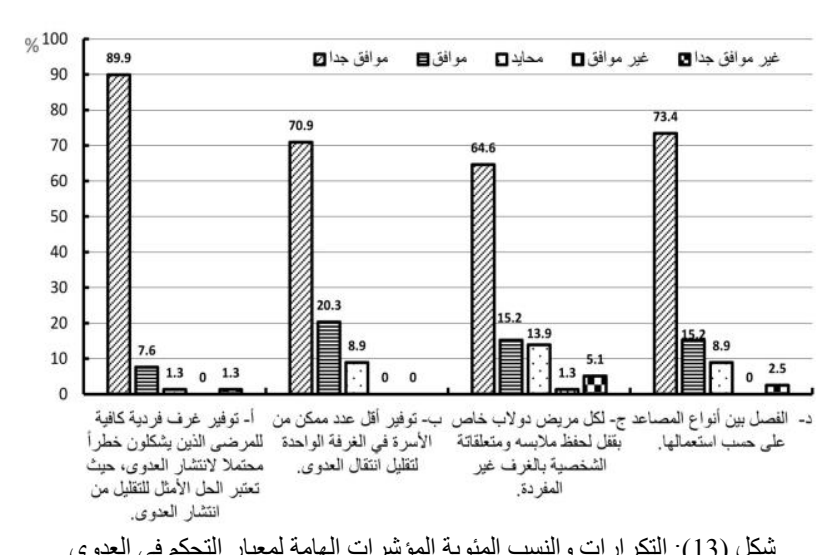

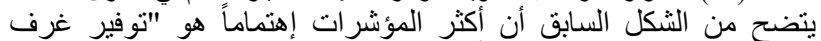

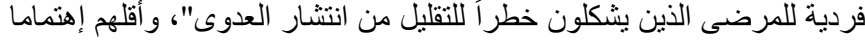

هو "لكل مريض دو لاب خاص بقفل لحفظ ملابسه ومتعلقاتة الشخصية".

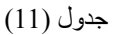

\begin{tabular}{|c|c|c|c|c|}
\hline الترتيب & 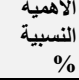 & المعياري & الحسابي المت & المؤشرات \\
\hline 2 & 97.00 & 0.55 & 4.85 & 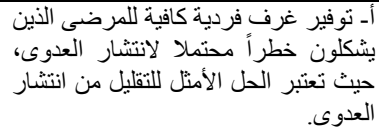 \\
\hline 1 & 92.40 & 0.64 & 4.62 & الغرفة توفير أقل عدة عدل ممكن من الأسرة في \\
\hline 4 & 86.60 & 1.09 & 4.33 & ملابسه لكل مريضعاتة دالثخصية بالغرف بقل غير لحفظ \\
\hline 3 & 91.40 & 0.85 & 4.57 & دـــمالها. بين أنواع المصاعد على حسب \\
\hline & 91.84 & 0.46 & 4.59 & المتوسط العام \\
\hline
\end{tabular}

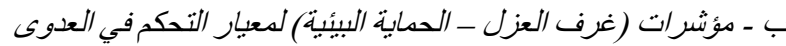

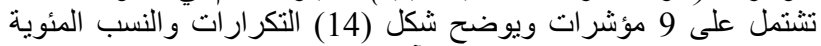
(غرف العزل - الحماية البيئية) وفقا لآراء العينة، وبحل (14) وبحساب قيم المؤشرات

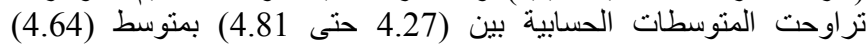
بانحر اف معياري (0.28).

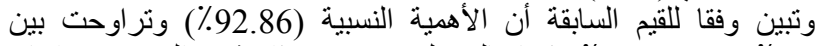

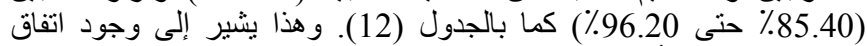

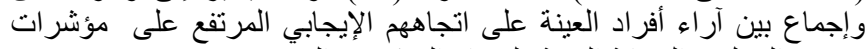

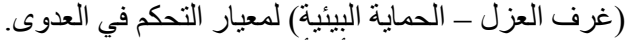

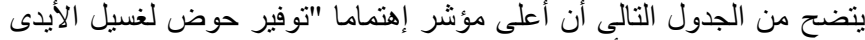

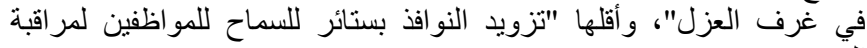

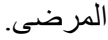

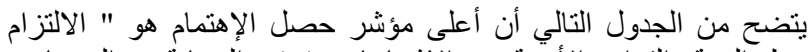

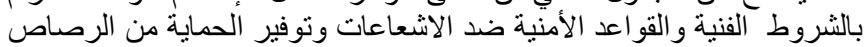

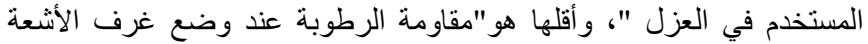

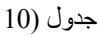

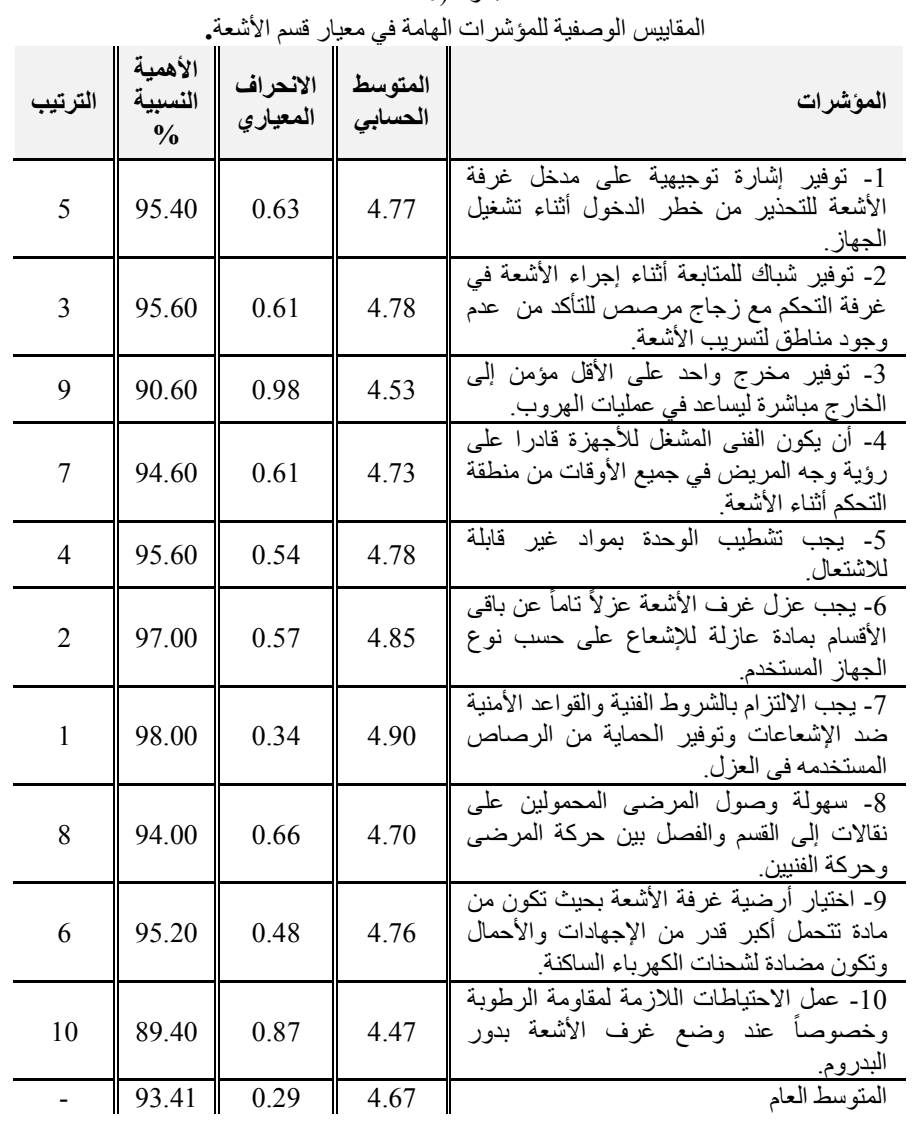

$$
\text { 7-2-3-4 معبار التحكم في العدوى: بقدي: }
$$

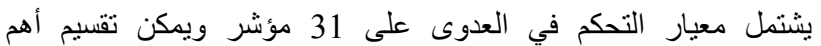

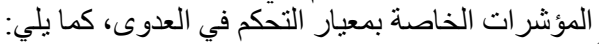
أـ المؤشرات الهامة في معبار التحكم في العدوى:

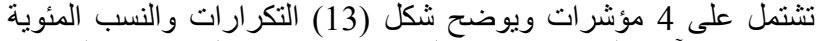

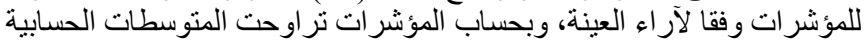
بين (4.33 حنى 4.85) بمتوسط (46.59) بانحر اف معياري (0.46) (0.40). وتر اوحت

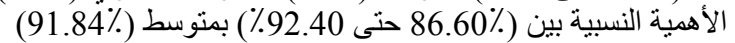

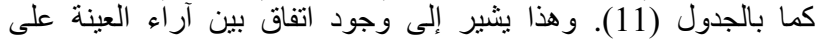
اتجاههم الإيجابي المرتفع على المؤشر ات الهامة في معيار التحكم في العدوى. لفئ العين على

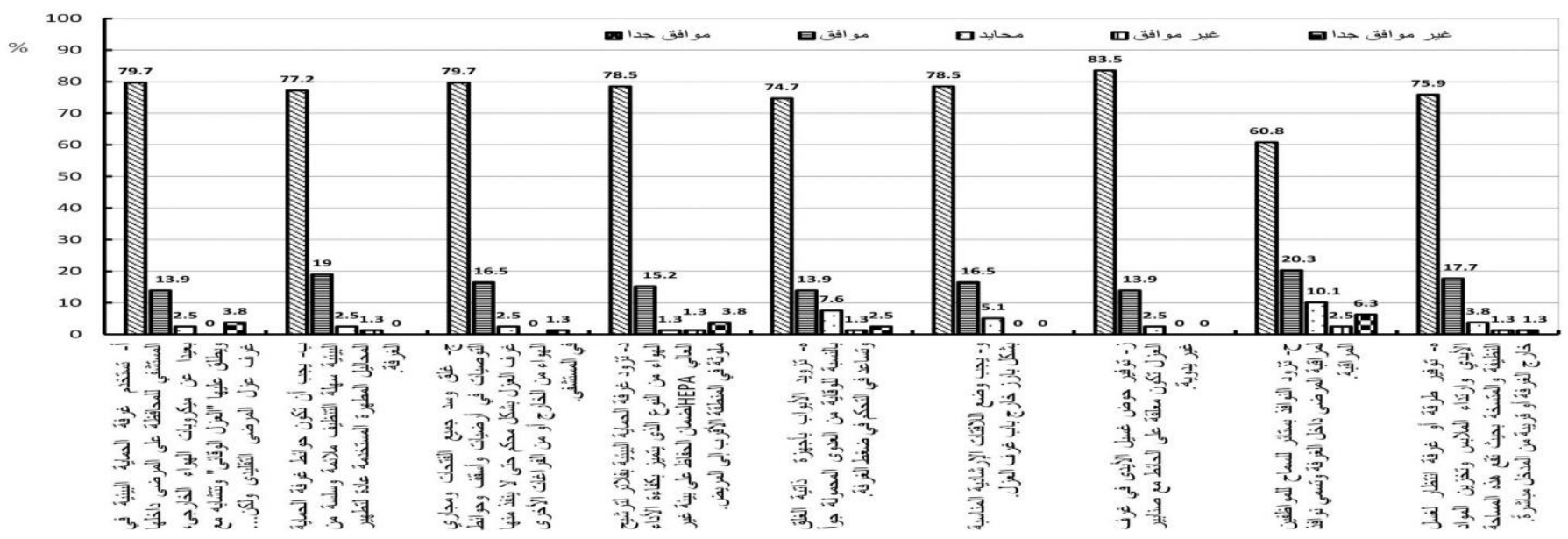




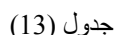

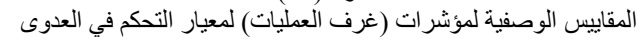

\begin{tabular}{|c|c|c|c|c|}
\hline الترتيب & الأهمية & 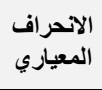 & المستوسط & المؤشرات \\
\hline 3 & 94.60 & 0.69 & 4.73 & 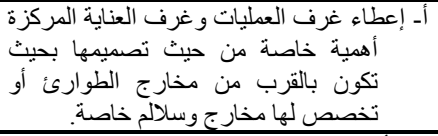 \\
\hline 4 & 94,00 & 0,75 & 4,70 & 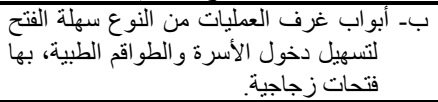 \\
\hline 5 & 89,20 & 0,97 & 4,46 & 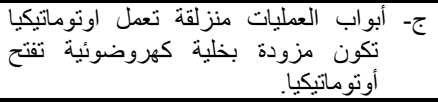 \\
\hline 2 & 96,80 & 0,51 & 4,84 & 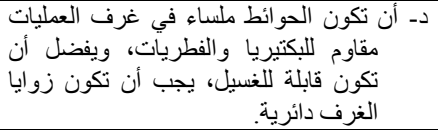 \\
\hline 1 & 98,00 & 0,30 & 4,90 & 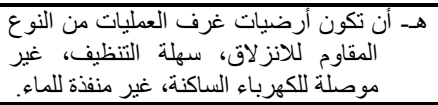 \\
\hline & 94,48 & 0,38 & 4,72 & المنوسط العام \\
\hline
\end{tabular}

دـ مؤشرات (خاصنة بالدغسلة) لمعيار التحكم في العدوى:

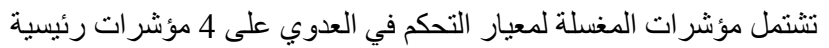

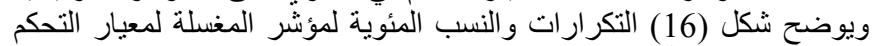

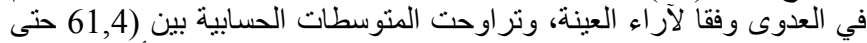

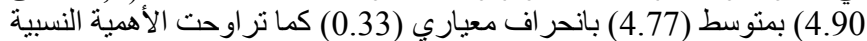

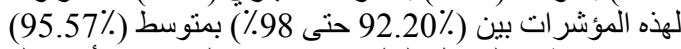

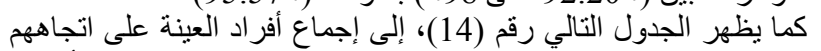

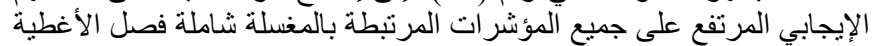

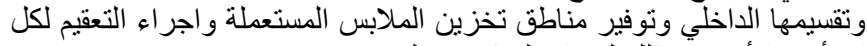
الالأت و الأجهزة وذللك لمعيار التحكم في العدوى.

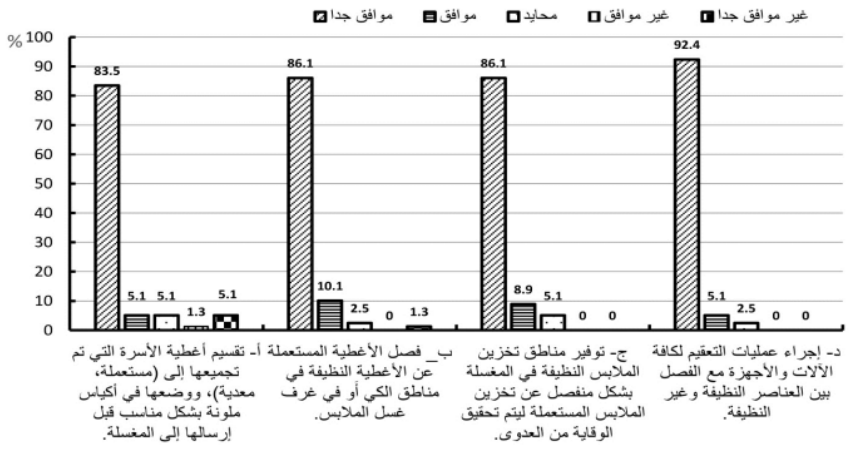

شكل (16): التكرار ات والنسب المئوية للمؤشر ات الخاصة بالمغسلة لمعيار التحكم في العدوى.

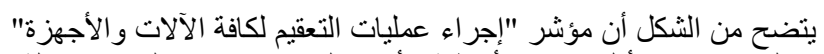
هو الاعلي اهتماما، و أقلها "تقسيم أغطية الأسرة التير التي تم تجميعها إلى (مستعملة،

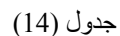

معدية).

المقاييس الوصفية للمؤشرات (خاصة بالمغسل)

\begin{tabular}{|c|c|c|c|c|}
\hline الترتيب & الاهمبية & 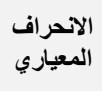 & المتوسط & المؤشرات \\
\hline 4 & 92.20 & 1.01 & 4.61 & 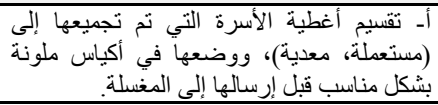 \\
\hline 3 & 96.00 & 0.60 & 4.80 & الملظيفة في مناطق الأغطية المستعملة عي غرف الأغطية \\
\hline 2 & 96.20 & 0.50 & 4.81 & 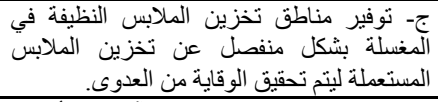 \\
\hline 1 & 98.00 & 0.37 & 4.90 & 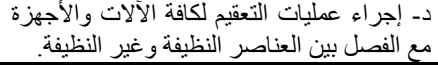 \\
\hline & 95.57 & 0.33 & 4.72 & المتوسط العام \\
\hline
\end{tabular}

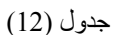

المقاييس الوصفية لمؤشرات (غرف العزل - الحماية البيئية) لمعيار التحكم في العدوى.

\begin{tabular}{|c|c|c|c|c|}
\hline ب الترتي & $\begin{array}{l}\text { الأهمية } \\
\text { \% } \\
\end{array}$ & 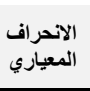 & 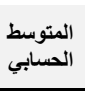 & المؤشرات \\
\hline 5 & 93.20 & 0.86 & 4.66 & 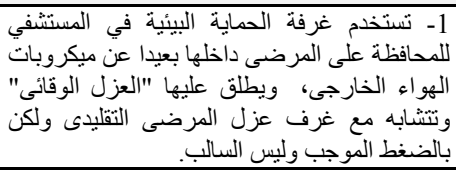 \\
\hline 4 & 94.40 & 0.57 & 4.72 & 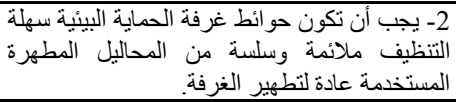 \\
\hline 2 & 94.60 & 0.63 & 4.73 & 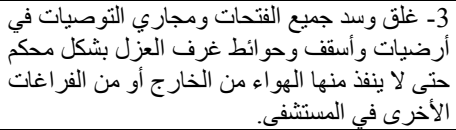 \\
\hline 7 & 92.60 & 0.89 & 4.63 & 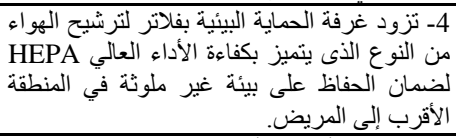 \\
\hline 8 & 91.40 & 0.88 & 4.57 & 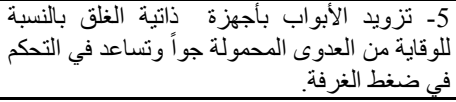 \\
\hline 3 & 94.60 & 0.54 & 4.73 & 6- بارز خارج وضابع غرف اللافتات الإرشادية المناسبة بشكل \\
\hline 1 & 96.20 & 0.45 & 4.81 & تكون معلقة على الحائط مع صنيل الأبدى في غير غرف العزل \\
\hline 9 & 85.40 & 1.15 & 4.27 & 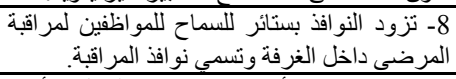 \\
\hline 6 & 93.20 & 0.73 & 4.66 & 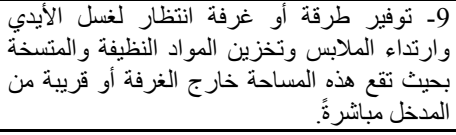 \\
\hline & 92.86 & 0.28 & 4.64 & المنوسط العام \\
\hline
\end{tabular}

ج- مؤشرات (غرف العدليات) لمعيار التحكم في العدوى

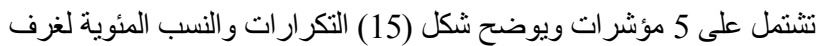

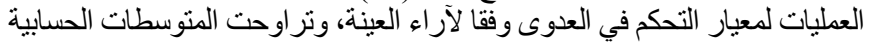
بين (4.46 حتى 4.90) بمتوسط (4.72) بانحر اف معياري (0.38) (0.30) كما تراوحت

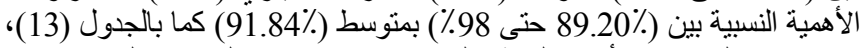
و هذا يشير إلى إجماع أفراد العينة على اتجاههم الإيجابي المرتفع على مؤشرات غرف العمليات لمعيار التحكم في العدوى.
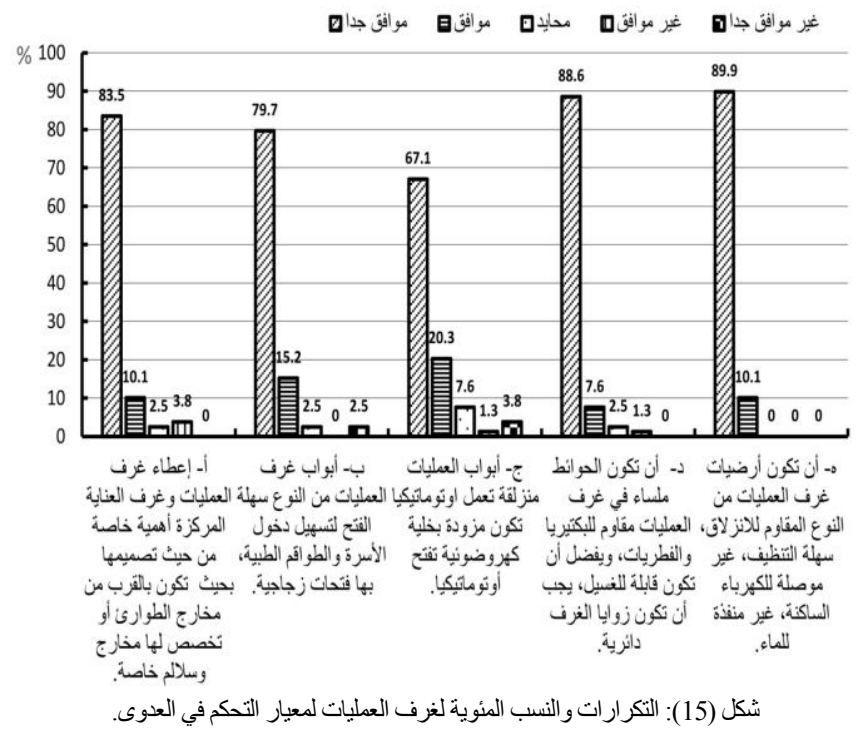

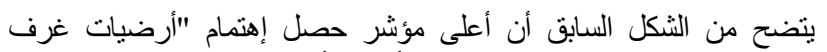

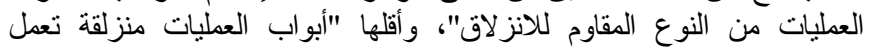

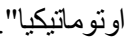


(4.56 : 4.78) بمتوسط (4.68) بانحر اف معياري (15.67. (0.31) و الأهمية النسبية بين

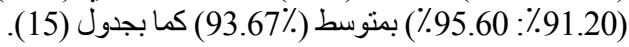

هـ مؤشرات (خاصة بالمطبخ) لمعبار التحكم في العدوى:

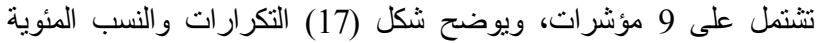

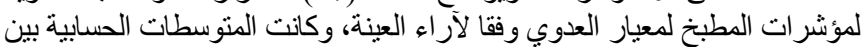

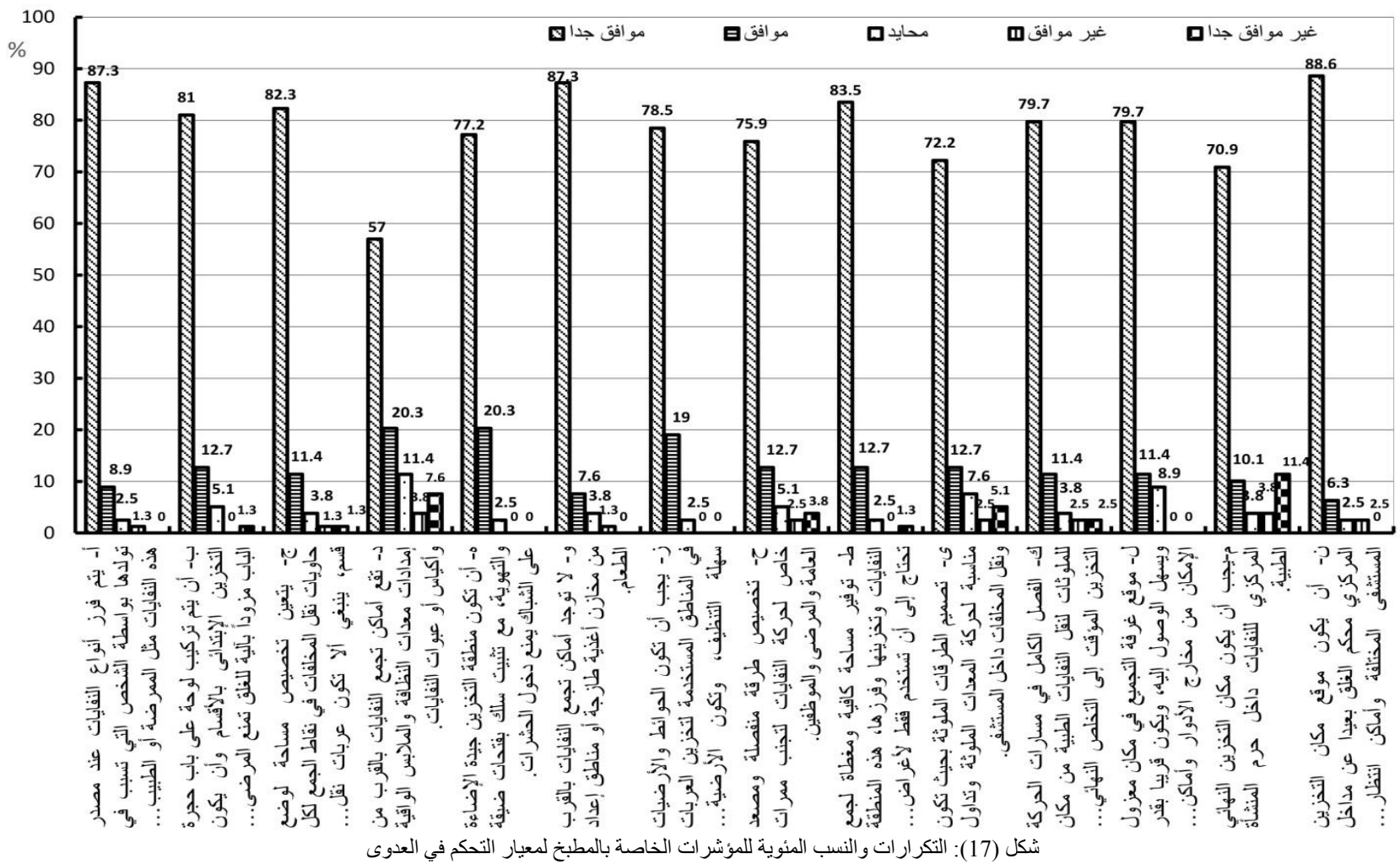

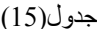

المقاييس الوصفية للمؤشر ات (خاصة بالمطبخ) لمعيار التحكم في العدوى المبر

\begin{tabular}{|c|c|c|c|c|}
\hline الترتيب & الأهمية النسبية \% & الانحراف المعياري & المتوسط الحسابي & المؤشرات \\
\hline 7 & 92.60 & 0.80 & 4.63 & 1- التأكد من تهوية المطبخ بشكل كافي وتركيب نظم تهوية اصطناعية مع إمكانية \\
\hline 2 & 95.20 & 0.68 & 4.76 & قابلة للتنظفيف بشكل أعلى معايير النظافة و التعقيم للمعدات، و اختيار تنطيبات بحيث تكون \\
\hline 4 & 94.00 & 0.75 & 4.70 & 3- الفصل في المطبخ بين الأغذية النيئة و المطبوخة. \\
\hline 5 & 93.60 & 0.79 & 4.68 & 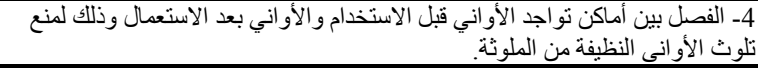 \\
\hline 9 & 91.20 & 0.85 & 4.56 & 5- أن تتقل الأو اني النظيفة للتخزين أو استخدامها في منطقة تتاول الطعام دون المرور \\
\hline 6 & 93.40 & 0.84 & 4.67 & 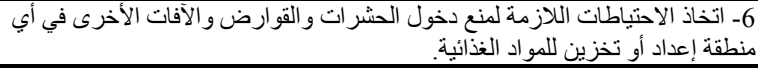 \\
\hline 8 & 92.20 & 0.83 & 4.61 & 7- فصل مناطق إعداد الطعام عن مناطق التوزيع. \\
\hline 3 & 95.0 & 0.53 & 4.75 & و الباردة. توفر عدد كاف من أحواض غسيل الأيدي و إمدادها بكمية كافية من المياه الساخنة \\
\hline 1 & 95.60 & 0.57 & 4.78 & 9- الإضـاءة الجيدة في جميع المناطق بما فيها مناطق التخزين البارد. \\
\hline- & 93.67 & 0.31 & 4.68 & المنوسط العام \\
\hline
\end{tabular}

بانحر اف معياري (0.24) كما تراوحت الأهمية النسبية بين (83.00\% وذنى

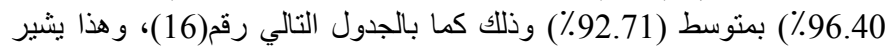

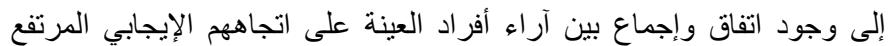

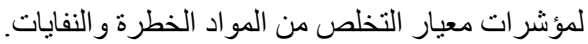

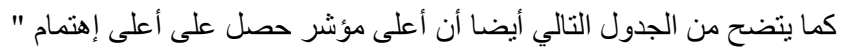

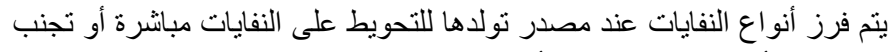

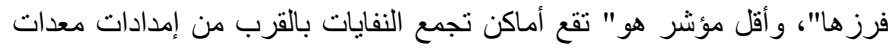

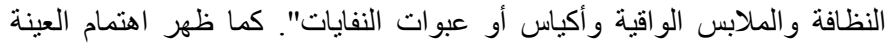
بجميع المؤشرات الممثلة لمعيار التخلص من المواد الد الخطرة والنفايات.
يتضح من الثكل السابق رقم (17) أن أعلى مؤشر حصل على إهتمام

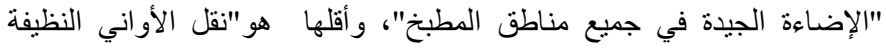

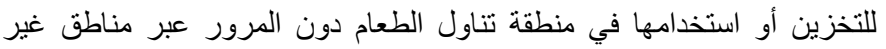

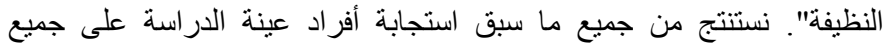
المؤشرات الممثلة للمطبخ لمعيار التحكم في العدوى واعطاها أهمية عالية ولكن بدرجات متفاو تة. 8-2-3-4 المؤشرات الهامة لمعبار التخلص من المواد الخطرة والنفايات. تشتنمل على 14 مؤشرات التكرارات والنسب المئوية للمعيار وفقا لآراء العينة، وتر اوحت المتوسطات الحسابية بين (4.15 حتى 14 (4.82) بمتوسط (4.63) 


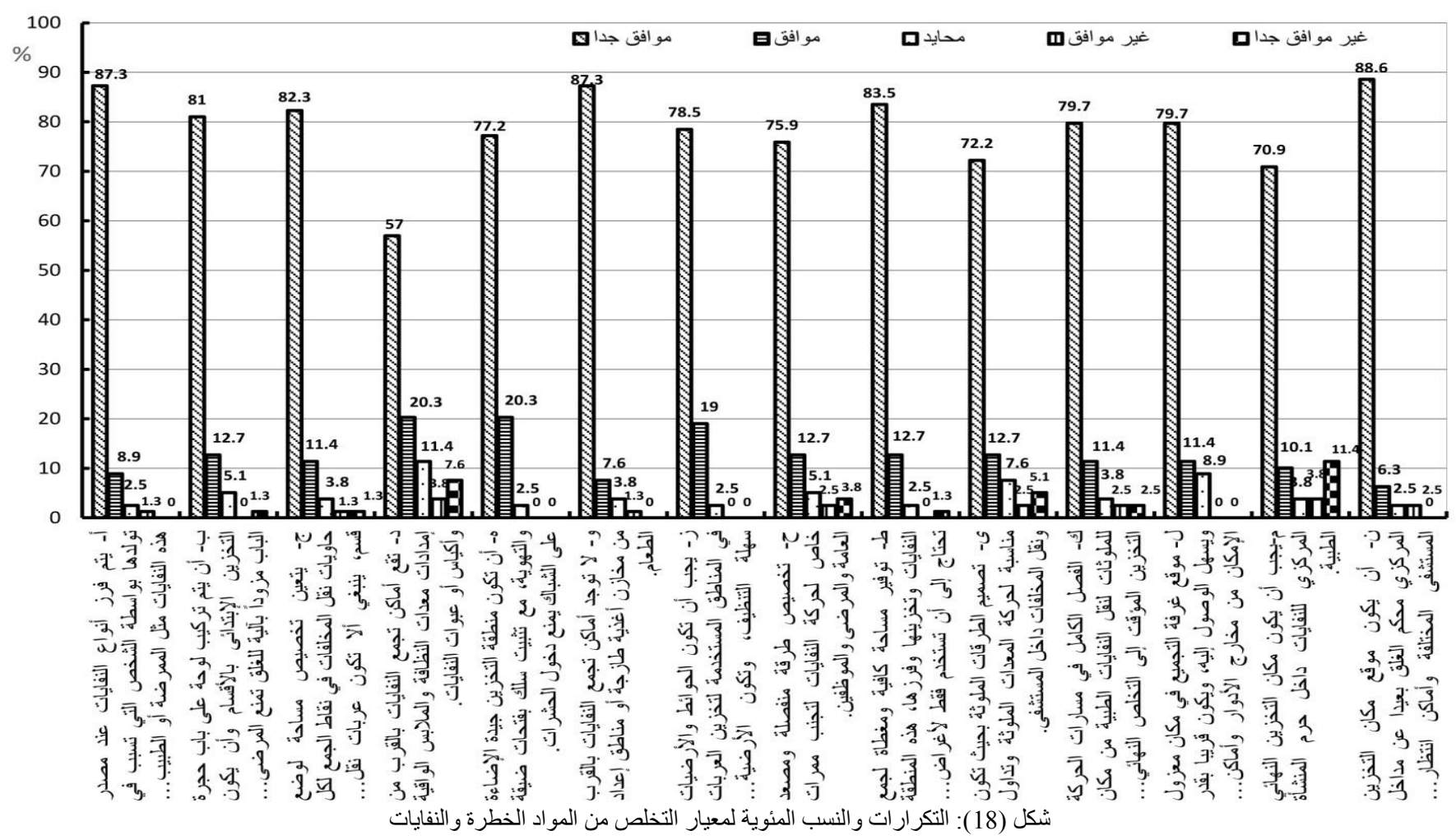

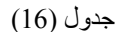

\begin{tabular}{|c|c|c|c|c|}
\hline الترتيب & النسبية الأهية & المعياري & المستوسط & المؤشرات \\
\hline 1 & 96,40 & 0,52 & 4,82 & 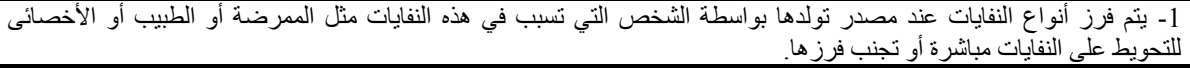 \\
\hline 7 & 94,40 & 0,67 & 4,72 & الدخول. أن يتم تركيب لوحة على باب حجرة التخزين الإبتدائى بالأقسام وأن يكون الباب مزوداً بآلية للغلق تمنع المرضى أو الزوار من \\
\hline 8 & 94,40 & 0,71 & 4,72 & 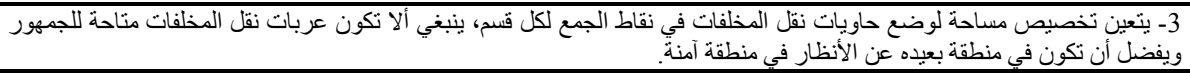 \\
\hline 14 & 83,00 & 1,23 & 4,15 & 4- تقع أماكن تجمع النفايات بالقرب من إمدادات معدات النظافة و الملابس الو اقية و أكياس أو عبو ات النفايات. \\
\hline 6 & 95,00 & 0,49 & 4,75 & 5- أن تكون منطقة التخزين جيدة الإضاءة و التهوية، مع تثيبت سلك بفتحات ضيقة على الثباكل يمنع دخول الحشر ات. \\
\hline 2 & 96,20 & 0,55 & 4,81 & 6- لا توجد أماكن تجمع النفايات بالقرب من مخازن أغذية طاز جة أو مناطق إعداد الطعام. \\
\hline 5 & 95,20 & 0,48 & 4,76 & 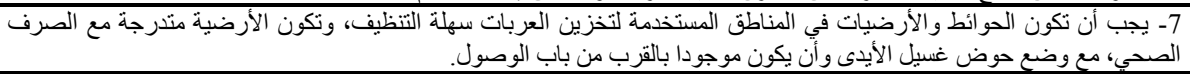 \\
\hline 11 & 90,80 & 0,98 & 4,54 & 8ـ تخصيص طرقة منفصلة ومصعد خاص لحركة النفايات لتجنب ممر ات العامة و المرضى و الموظفين. \\
\hline 4 & 95,40 & 0,61 & 4,77 & المساحة تبعا لحجم المنشأة. ومغطاة لجمع النفايات وتخزينها وفرز ها، هذه المنطقة تحتاج إلى أن تستخدم فقط لأغر اض إدارة النفايات وتحدد \\
\hline 12 & 88,80 & 1,08 & 4,44 & 10 - تصميم الطرقات الملوثة بحيث تكون مناسبة لحركة المعدات الملوثة وتداول ونقل المخلفات داخل المستشفى. \\
\hline 10 & 92,60 & 0,88 & 4,63 & 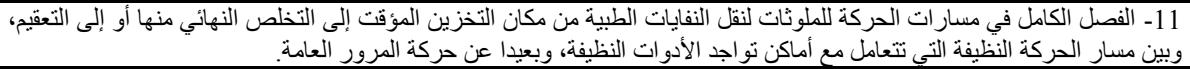 \\
\hline 9 & 94,20 & 0,62 & 4,71 & الداخلية، وبعيدة عن أنماكيع فقيديم الطعام. معزول ويسهل الوصول إليه، ويكون قريبا بقدر الإمكان من مخارج الأدوار وأماكن السلالم و الدصاعد \\
\hline 13 & 85,00 & 1,37 & 4,25 & 13- يجب أن يكون مكان التخزين النهائي المركزي للنفايات داخل حرم المنشأة الطبية. \\
\hline 3 & 96,20 & 0,61 & 4,81 & مصدر الر ائحة كريهة مكو الضوض التخزين. المركزي محكم الغلق بعيدا عن مداخل المستثفى المختلفة وأماكن انتظار السيارات، لكي لا يكون \\
\hline - & 92,71 & 0,24 & 4,63 & المت سב \\
\hline
\end{tabular}

ترتيب درجات أهمية معايير الجودة الهندية بالجدول (1)، وتبين منه أن أن أنديا

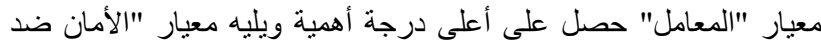

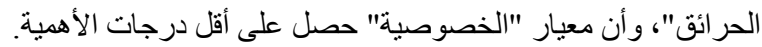

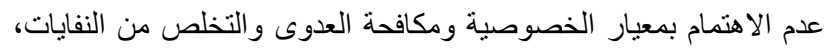

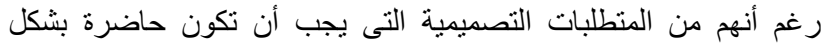
أساسي في أذهان و اعتبار ات المتخصن التصنين. تحديد ترتيب لدرجة أهمية كل المؤشرات أنيات الداخلية التابعة لكل معيار رئيسى وتبين التأكيد علي أهمية تطبيقهم جميعاً ولكن بنسب متفاوتة ولته وفقاً للأهمية.

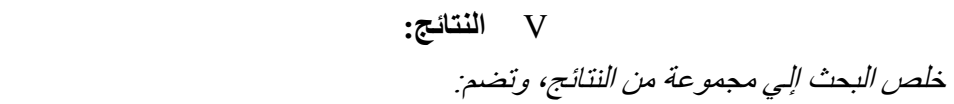

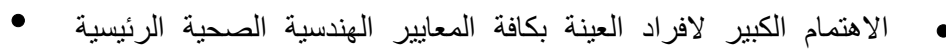

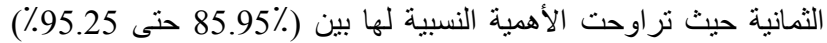
بصورة تؤكد انها أساسية ومهمة لتفعيل نظام جودة الخدمات الصحية. 


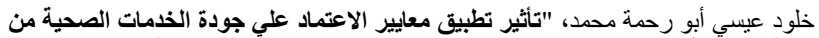

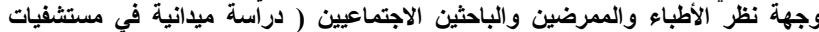

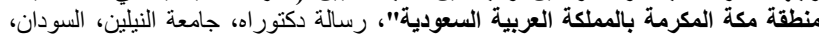
2016

سارة داى، "فعالية إدارة الجودة الثاملة في تحسين العلاقة مع الزبون،(دراسة حالة

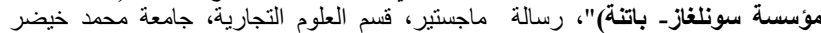
بسكرة، الجزائر، سعدي الكحلوت محمد، "العوامل المؤثرة على استمرارية أنشطة الجودة الثاملة في في فئي

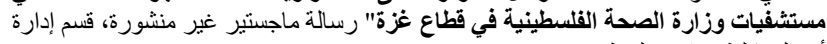

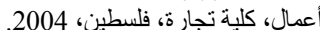

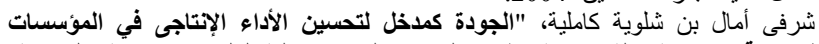

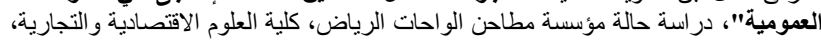

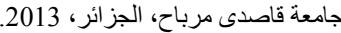

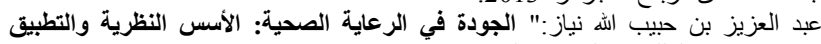

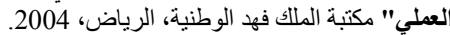

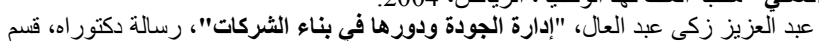

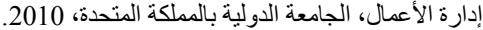

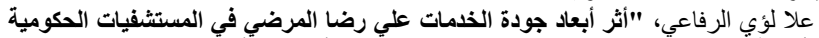

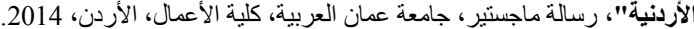

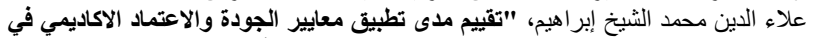

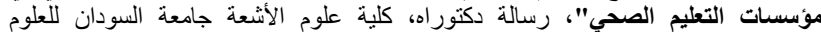

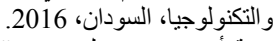
[12] هبة أحمد حسين على سيد، "إدارة الجودة الثاملة الثلة بين النظرية والتطبيق في المؤسسات

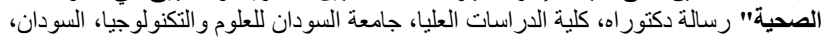
2015

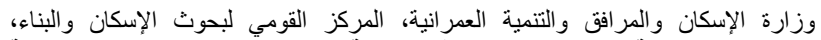

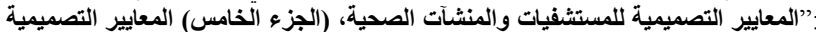

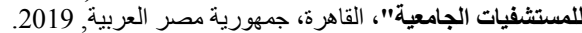

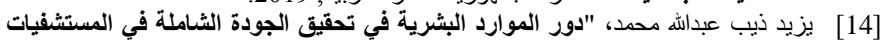

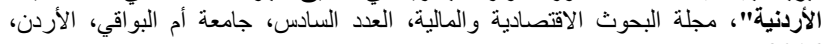
2016

[15] Ministry of Health and Population, "Standards for Hospitals ", Egyptian HealthCare Accreditation Program, Training and Research Sector, Accreditation Executive committee, Second Edition, 2013.

[16] Tamimi, Nabil and Sebasttianelli, Rose, "How firms define and measure quality", Production and inventory management, (1996). [Online] journal 37,no.3.

Available:https://www.scribd.com/doc/89471660/How-Firms-Defineand-Measure-Quality

[17] http://www.mohp.gov.eg/SectorServices.aspx

\section{Title Arabic:}

\section{المعايير الهندية لتحقيق جودة الذذمات الصحية في المستثفيات

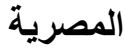

\section{Arabic Abstract:}

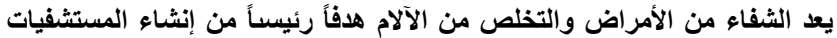

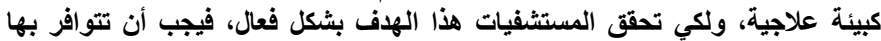

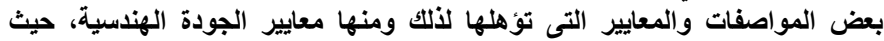

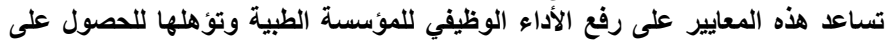

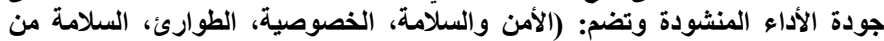

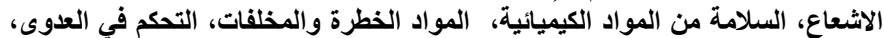

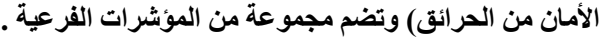

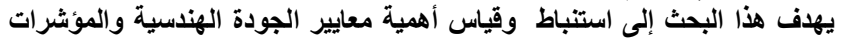

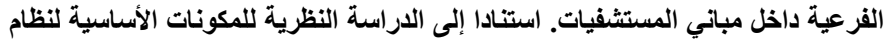

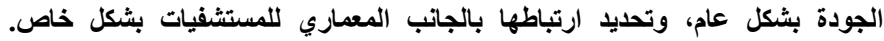

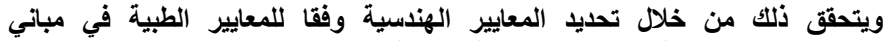

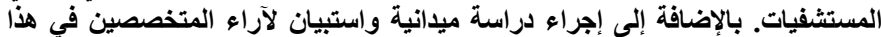

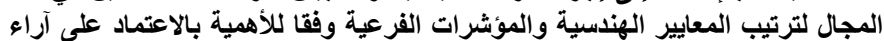
العينة ونتائج الاراسة الميدانية.
اتفاق أفراد العينة (نسب تزيد عن 90\%) على أهمية تطبيق جميع المعايير

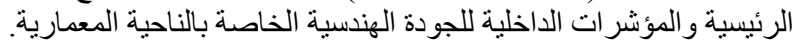

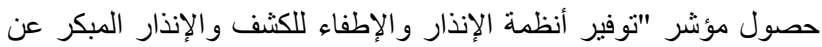

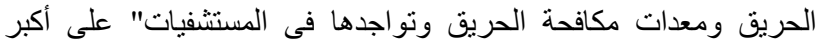

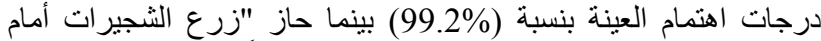

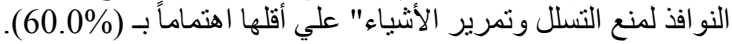

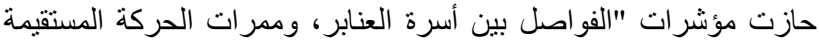

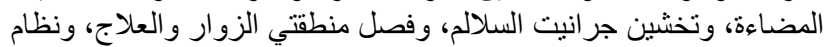

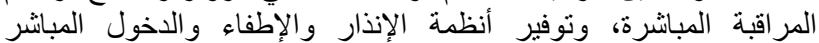

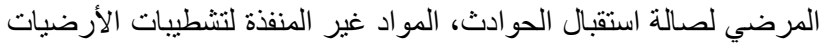

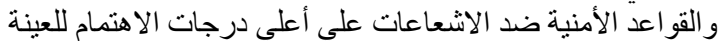

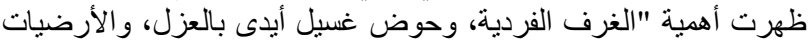

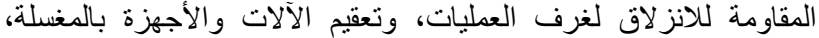

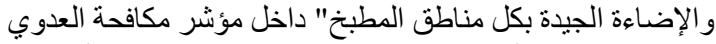

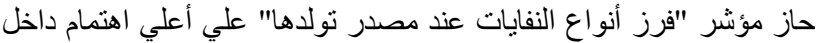

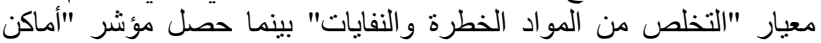

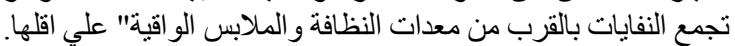

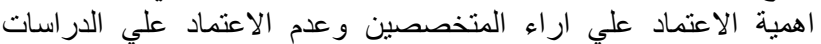
النظرية وفقط لوجود اختلافات ناتجة عن منطلبن ولات الات الممارسة الفعلية

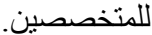

\section{VI}

بناء على ما قام به البحث من دراسة وما توصل إليه من نتائج يوصي البحث

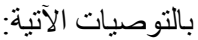

1- الاهتمام بتحقيق معايير الجودة بالمستشفيات مع الاهتمام بمراقبة التطبيق الإنيق

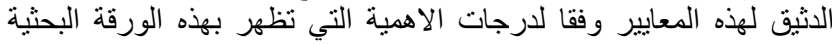

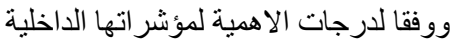

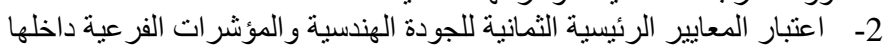

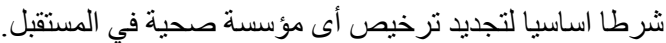

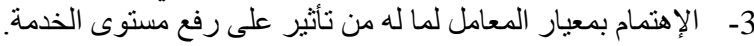

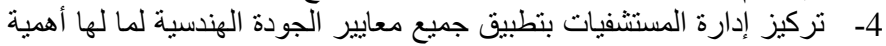

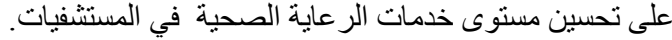

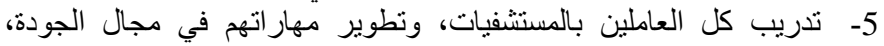

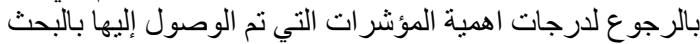

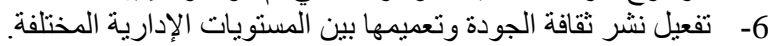

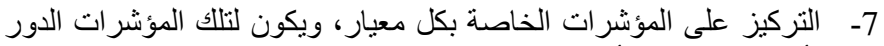

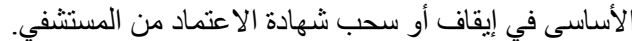
8- توسيع دائرة الاهتمام بالمؤشرات الداخلية التي حصلت علي ألئي أعلي درجات اهتمام افر اد العينة

9- مخاطبة الجهات المعنية بعمل دليل ارشادي لتوضح آليات تنفيذية لتطبيق

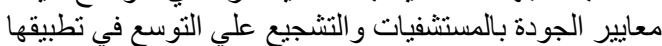

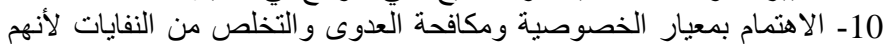

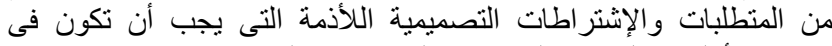
صدارة الأولويات لمعايير الجودة في المستشفيات المصرية.

$$
\text { المراجع }
$$

إبراهيم ناصر سيف، "أثر تطبيق معايير الاعتماد علي الإبداع في المستثفيات العامة

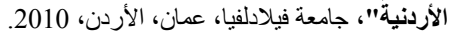

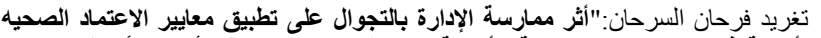

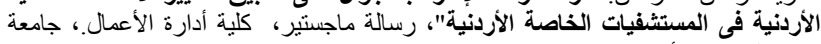

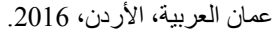

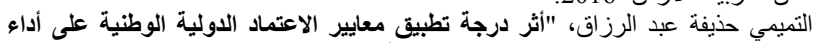

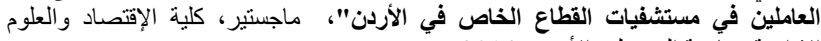

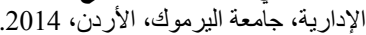

